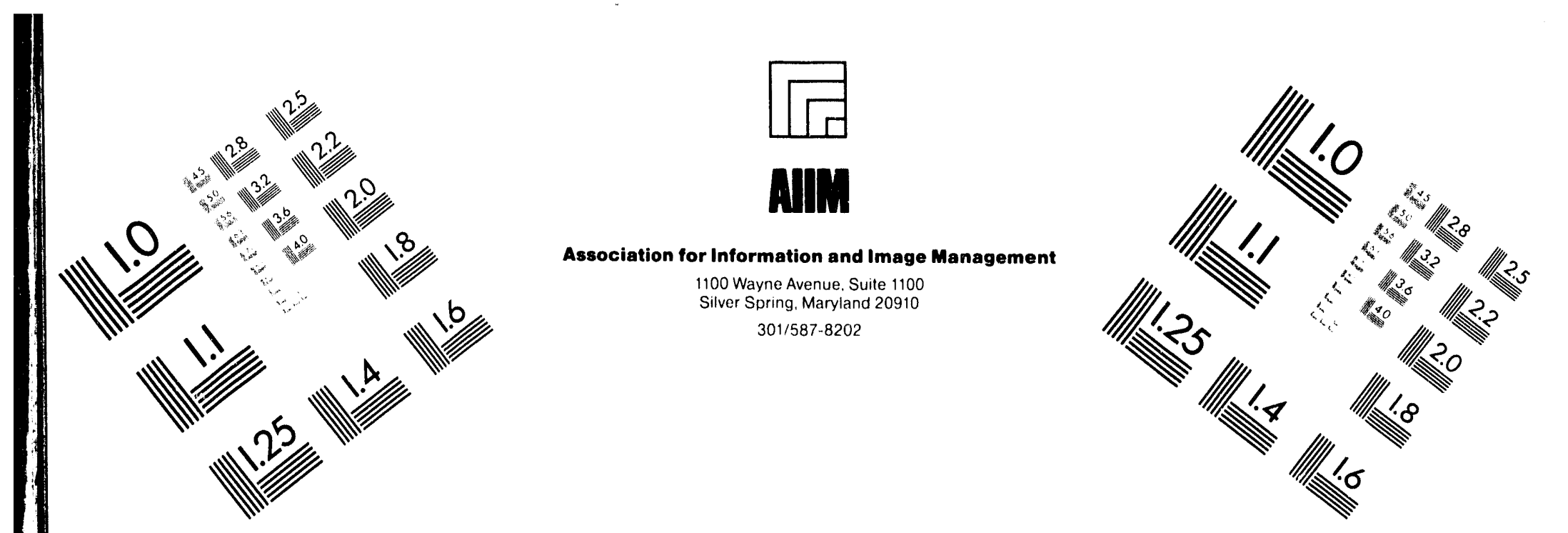

\title{
Centimeier
}

1m Inches
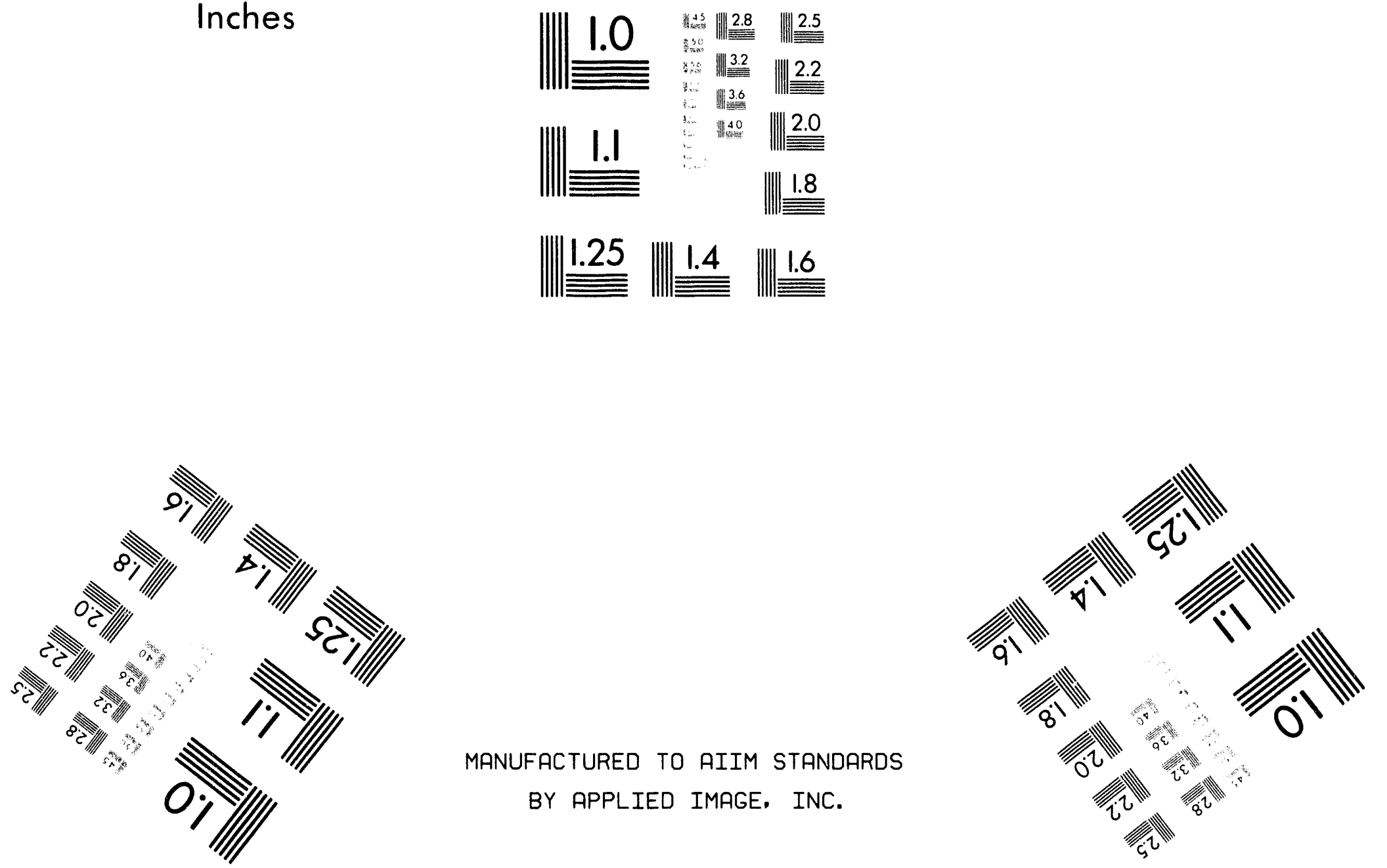

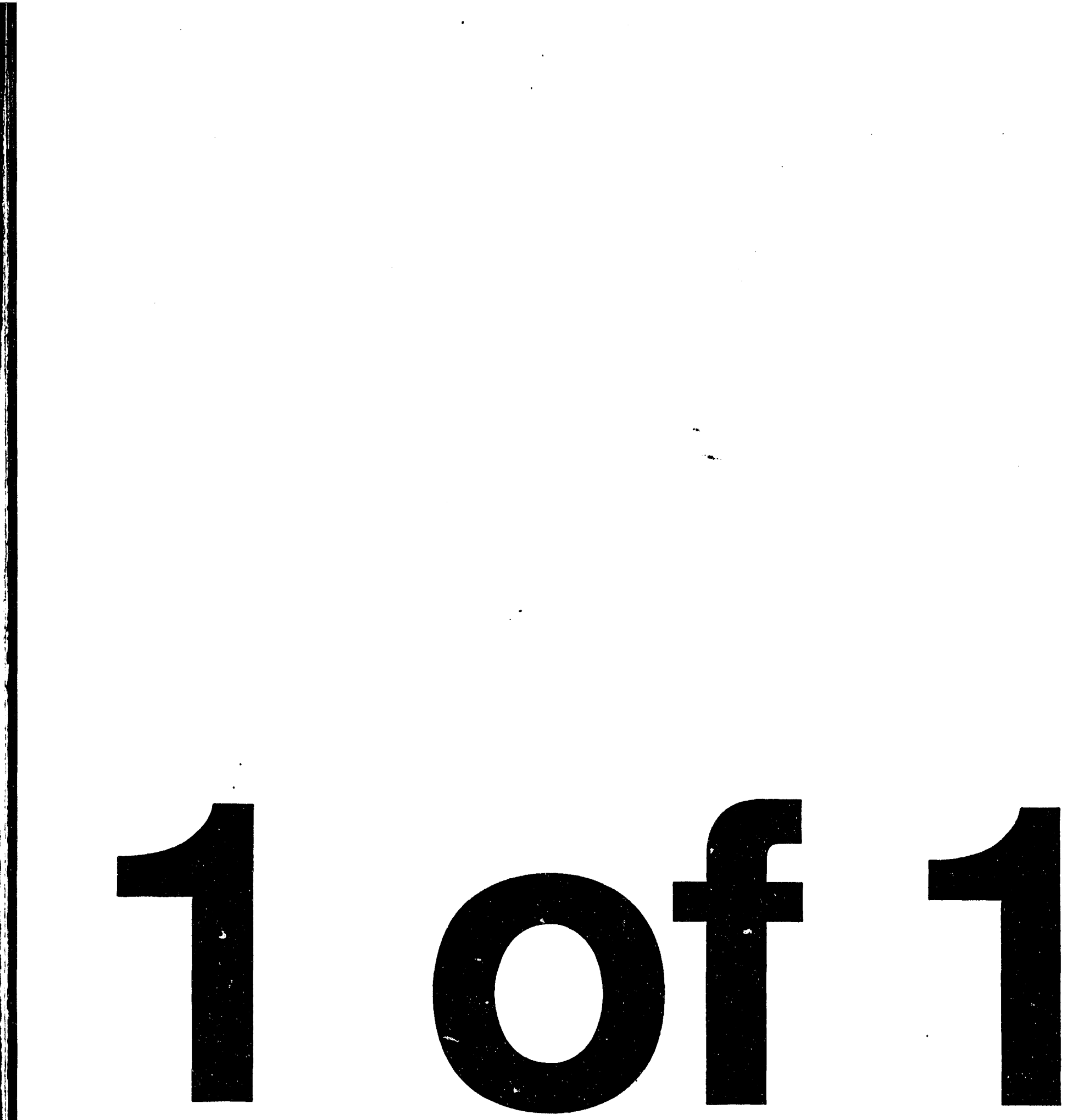


\section{NUCLEAR CRITICALITY SAFETY ASSESSMENT OF THE LOW LEVEL RADIOACTIVE WASTE DISPOSAL FACILITY TRENCHES (U)}

\section{S.D. KAHOOK}

APRIL 1994

ADC \&

Reviewing Official:

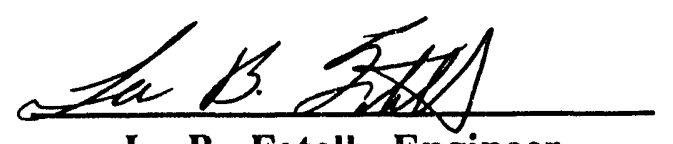

L. B. Fatell, Engineer

Date:

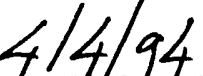

Westinghouse Savannah River Company

Savannah River Site

Alken, SC 29808

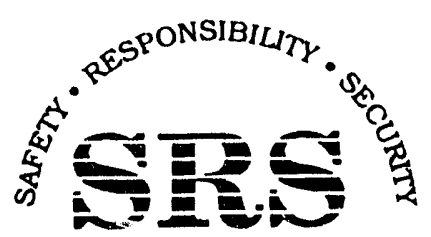

PREPARED FOR THE U.S. DEPARTMENT OF ENERGY UNDER CONTRACT NO. DE-AC09-89SR18035 
This report was prepared by Westinghouse Savannah River Company (WSRC) for the United States Deportment of Energy under Contract No. DE-AC0989SR 18035 and is an account of work performed under that contract. Neither the United States Department of Energy, nor WSRC, nor any of their employees makes any warranty, expressed or implied, or assumes any legal liability or responsibility for the accuracy, completeness, or usefulness, of any information, apparatus, or product or process disclosed herein or represents that its use will not infringe privately owned rights. Reference herein to any specific commercial product, process, or service by trademark, name, manufacturer or otherwise does not necessarily constitute or imply endorsement, recommendation, or favoring of same by WSRC or by the United States Government or any agency thereof. The views and opinions of the authors expressed herein do not necessarily state or reflect those of the United States Government or any agency thereof. 
WSRC-TR-94-0127

\title{
SAFETY TECHNOLOGY DEPARTMENT
}

\author{
Key Words: Burial Grounds \\ Waste Containers \\ Enriched Uranium \\ Monte Carlo

\section{NUCLEAR CRITICALITY SAFETY ASSESSMENT OF THE LOW LEVEL RADIOACTIVE WASTE DISPOSAL FACILITY TRENCHES(U)}

by

S.D. Kahook

Contributors:

N.P. Baumann

S.P. Harris

S.D. Kahook

M.J. Murnan

J.H. Weber

T.G. Williamson

R.S. Wittman

Issued: APRIL 1994

Westinghouse Savannah River Company

Savannah River Site

Alken, SC 29808

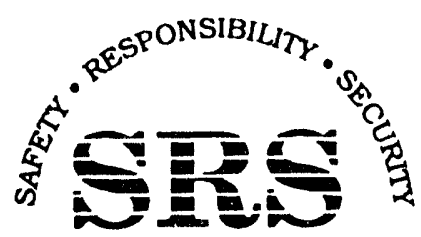

SAVANNAH RIVER SITE

PREPARED FOR THE U.S. DEPARTMENT OF ENERGY UNDER CONTRACT NO. DE-AC09-89SR18035 
THIS PAGE INTENTIONALLY LEFT BLANK. 
Project: $\quad$ LLRWDF Closure

Document: WSRC-TR-94-0127

Title:

NUCLEAR CRITICALITY SAFETY ASSESSMENT OF THE LOW LEVEL RADIOACTIVE WASTE DISPOSAL FACILITY TRENCHES (U)

Approvals:

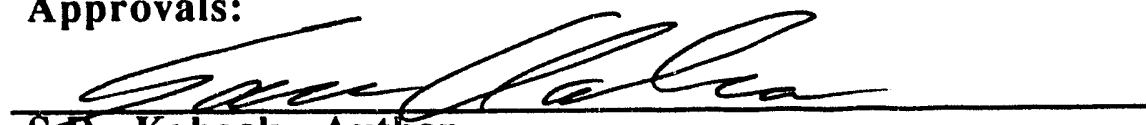

S.D. Kahook, Author $\frac{3-31-94}{\text { Date }}$

Enviropmental Analysis and Solid Waste Group haymond L feed

R.L. Reed, Technical Reviewer Applied Physics Group

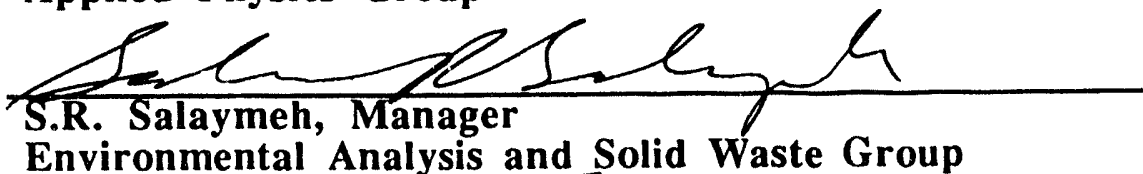
$3-31-94$

Environmental Analysis and Solid Waste Group
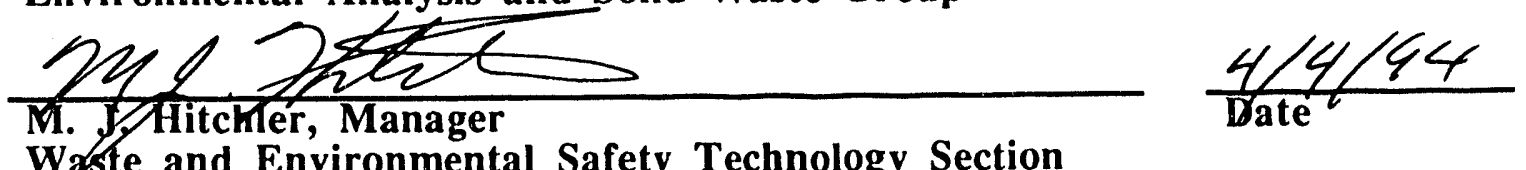

Waste and Environmental Safety Technology Section

Westinghouse Savannah River Company Savannah River Site Aiken, SC 29808

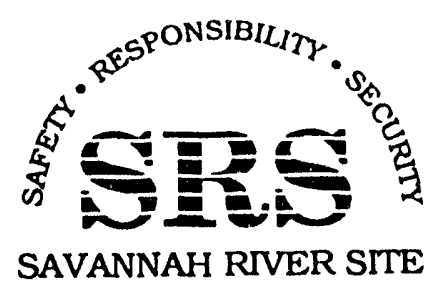

PREPARED FOR THE U.S. DEPARTMENT OF ENERGY UNDER CONTRACT NO. DE-AC09-89SR18035 
THIS PAGE INTENTIONALLY LEFT BLANK. 


\section{EXECUTIVE SUMMARY}

Results of the analyses performed to evaluate the possibility of nuclear criticality in the Low Level Radioactive Waste Disposal Facility (LLRWDF) trenches are documented in this report. The studies presented in this document are limited to assessment of the possibility of criticality due to existing conditions in the LLRWDF. Since the analyses presented in this document address criticality concerns for a static process, i.e., for a facility, namely the LLRWDF trenches, in which operations have ceased, this document does not propose nor set limits for EU burial in the LLRWDF and is not a nuclear criticality safety evaluation nor analysis. The calculations presented in this report are Level 2 calculations as defined by the E7 Procedure 2.31 [1], "Engineering Calculations."

Despite conservative assumptions and large margins of safety employed throughout the analyses, the study concluded that the potential of a nuclear criticality in the asis configuration of the LLRWDF is incredible, i.e., $<10^{-06}$. The combined probability of a criticality in the LLRWDF is conservatively estimated to be $0.47 \times$ 10-06. Written procedures as well as verbal accounts of actual operations indicate that efforts were made to separate waste containers containing a high content of EU. Consideration of such operations contributes to making the probability of a criticality in the LLRWDF much lower than the calculated $0.47 \times 10^{-06}$. 
THIS PAGE IS INTENTIONALLY LEFT BLANK 


\section{CONTEN'TS}

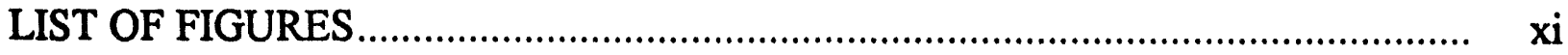

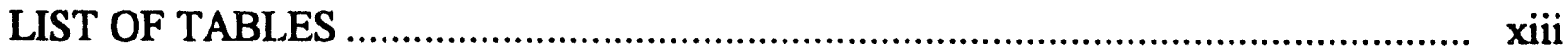

GLOSSARY AND LIST OF SYMBOLS ….....................................................

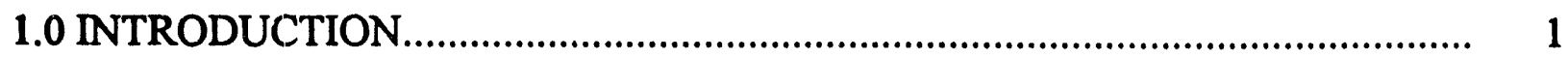

1.1 INTRODUCTION AND PURPOSE .................................................... 1

1.2 SUMMARY OF ANALYSIS AND RESULTS ....................................... 2

1.3 ACKNOWLEDGMENT .................................................................. 3

1.4 REPORT ORGANIZATION ........................................................... 3

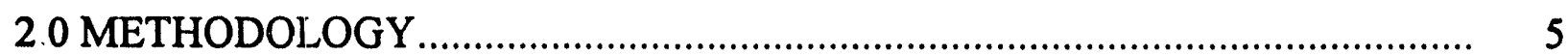

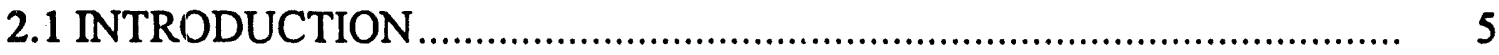

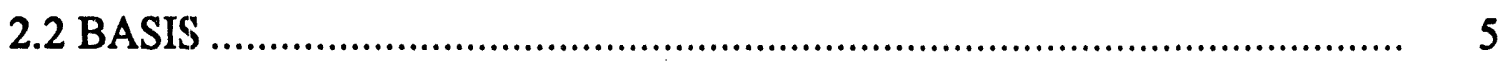

2.3 CALCULATIONAL TOOLS \& METHODS .......................................... 6

2.3.1 Nuclear Criticality Safety Codes ................................................. 6

2.3.2 Volume of Intersecting Bodies ................................................ 10

3.0 DESCRIPTION OF MODELS ................................................................. 11

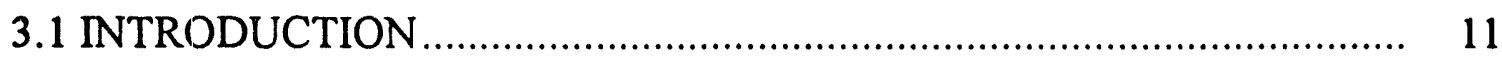

3.2 DESCRIPTION OF LLRWDF CONTAINERS …............................. 11

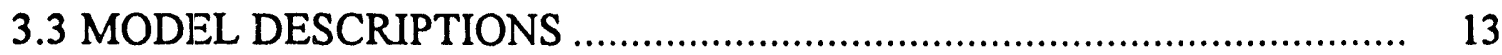

3.3.1 Description of the KENO/CG Models....................................... 13

3.3.2 Description of Materials Employed in the Analysis....................... 17

3.3.3 Description of the Statistical Models.......................................... 20

3.3.4 Assay Uncertainties ............................................................ 23

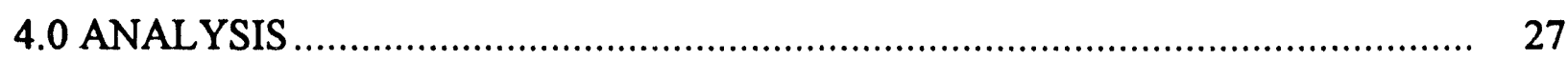

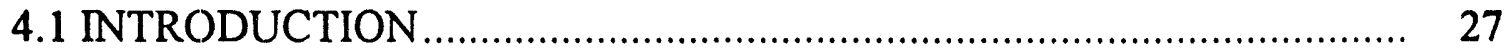

4.2 REACTIVITY CALCULATIONS AND ANALYSIS ............................. 27

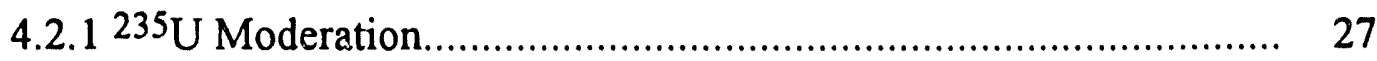

4.2.2 External Reflector............................................................ 29

4.2.3 Intermediate Reflector Region ............................................. $\quad 30$

4.2.4 Internal Reflector ................................................................ 30

4.2.5 Container's Separation Distance ............................................ 32

4.2.6 Neutronic Interaction Among the Containers ............................. 33

4.2.7 Mass Distribution Among the Containers................................... 34

4.2.8 Sub-Critical Loading............................................................ 34

4.3 STATISTICAL ANALYSIS ........................................................... 36 
5.0 SUMMARY OF RESULTS AND CONCLUSIONS ……………………….......... 37

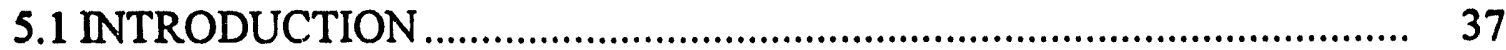

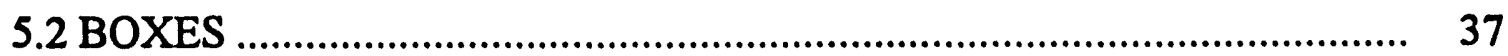

5.3 SIX AND FIVE DRUMS …….................................................... 38

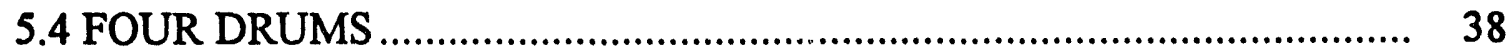

5.5 INTERACTING BOXES AND DRUMS.......................................... 38

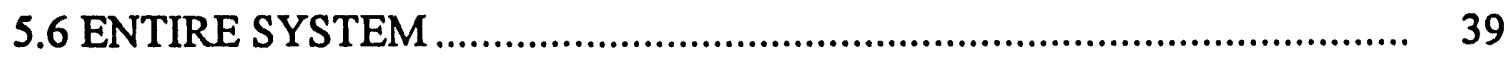

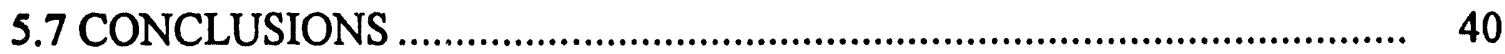

6.0 REFERENCES

$\begin{array}{lr}\text { APPENDIX A } & 43\end{array}$ 
2-1. Schematic of the Model Used in the KENO/ANISN Comparison Study ............. 9

3-1. Schematic and Dimensions of the B-25 Box "Waste Container" ........................ 12

3-2. Schematic and Dimensions of the 55-Gallon Drums, Type DOT-17C ................ 12

3-3. Schematic of the Four B-25 Box Configuration Model .....................................

3-4. Schematic of the Six 55-Gallon Drum Configuration Model ............................... 15

3-5. Schematic of the Four 55-Gallon Drum Configuration Model ........................... 16

3-6. Schematic of the Two Box/Two Drum Configuration Model ............................. 16

3-7. Schematic of the Drum Stacking Model for the Expectation Values Calculations.

4-1. Reactivity of a Four Drum System as a Function of $235 \mathrm{U}$ Moderation in Polyethylene

4-2. Calculated $\mathrm{K}_{\text {eff }}$ as a Function of the Void Fraction in the Internal Reflector (Polyethylene). 
THIS PAGE IS INTENTIONALLY LEFT BLANK 


\section{LIST OF TABLES}

2-1. Comparison Between ANISN and KENO Calculations For Various H:235U Ratios

3-1. Dimensions of the B-25 Box "Waste Container"

3-2. Dimensions of the 55-Gallon Drums

3-3. List of Materials Employed in the Five Regions of All Interacting Systems

3-4. Composition of Selected Materials Employed in this Study

3-5. Composition of the SRS Soil Employed in This Study

4-1. Optimum ${ }^{235} \mathrm{U}$ Density in Polyethylene for the Different Examined Configurations

4-2. Neutron Multiplication Factor as a Function of the Composition of the Intermediate Reflector Region.

4-3. Reactivity of the Four Drum Configuration as a Function of the Composition of the Container's Internal Reflector Region

4-4. Reactivity of the Four Drum Configuration as a Function of the Separation Distance Between the Drums

4-5. $\mathrm{K}_{\mathrm{eff}}$ as a Function of the Fissile Material Distribution Within the Containers

4-6. $K_{e f}$ as a Function of the Fuel Distribution Among the Containers

4-7. 235U Safe Loading

4-8. Expectation Values for Drum Combinations Exceeding Minimum Critical Mass 
THIS PAGE IS INTENTIONALLY LEFT BLANK 


\subsection{INTRODUCTION}

\subsection{INTRODUCTION AND PURPOSE}

During the time period of 1987 to 1989 , large amounts of enriched uranium ${ }^{1}$ (EU) were buried in the Low Level Radioactive Waste Disposal Facility (LLRWDF) as a result of the closing and decontamination of the Naval Fuels Facility. Prior to being buried in the LLRWDF the EU was placed in special waste containers (B-25 boxes and 55-gallon drums). ${ }^{2}$

Prior to the closure and decontamination of the Naval Fuels Facility, the majority of waste containers sent to the LLRWDF contained less than 200 grams of EU. ${ }^{3}$ However, closure of the Naval Fuels Facility resulted in large amounts of EU (more than $100 \mathrm{~kg}$ ) being buried in the LLRWDF and burial grounds records indicate that more than one hundred individual waste containers had more than 200 grams of EU each [3].

Waste Management Operations (WMO) procedures were used to separate the containers with EU to prevent possible criticality during normal operations [4]. However, an investigation of LLRWDF trench records, for the Engineered Low-Level Trenches (ELLTs) 2, 3, and 4 and 28 slit trenches, revealed that some sections contain sufficient amounts of EU such that the possibility of criticality cannot be ruled out without further studies [3]. ELLT 4 and 21 of the 28 slit trenches were found to be safe from a criticality standpoint. Sections were judged to be safe from a criticality standpoint if one of these two conditions were applicable [3]:

(1) the entire section contains less than 700 grams of ${ }^{235} \mathrm{U},{ }^{4}$ or

2 the containers with greater than 115 grams of $235 \mathrm{U}$ were widely separated (e.g., $40 \mathrm{ft}$.).

Following these findings, Westinghouse Savannah River Company (WSRC) decided to perform further analyses in order to assess the nuclear criticality safety of ELLT 2 and ELLT 3 and the seven remaining slit trenches of the LLRWDF: E17.40, N31.20, N31.50, N21.50, N11.90W, E29.60, and N19.30.

1 Enriched uranium implies that the percentage of ${ }^{235} \mathrm{U}$ is increased above its natural value.

2 The geometry and material used in constructing these containers are described in detail in Section 3.1 of this report.

3 There are only four incidents in which more than 200 grams of EUreached the burial grounds in any single container [3].

4 The maximum mass of ${ }^{235} U$ that will remain subcritical under uniform composition and distribution and optimum moderation and reflection is $700 \mathrm{grams}$ [5]. 
The purpose of this report is to document results of the analyses performed to evaluate the possibility of nuclear criticality in the LLRWDF trenches that were determined in Reference 3 to fail criteria 0 or 2 listed on page 1 of this document. The studies presented in this document are limited to assessment of the possibility of criticality due to existing conditions in the LLRWDF. Since the analyses presented in this document address criticality concerns for a static process, i.e., for a facility, namely the LLRWDF trenches, in which operations have ceased, this document does not propose nor set limits for EU burial in the LLRWDF and is not a nuclear criticality safety evaluation nor analysis.

The work presented in this document was performed under work plan SRT-EAG-938002, Criticality Analysis for LLRWDF Trenches $(U)$ [6]. Although the analyses presented in this document were performed prior to issuance of the E7 Procedure Manual, "Conduct of Engineering and Technical support (U) [1]," the analyses do conform to Level 2 calculations as defined by the E7 Procedure 2.31 [1], "Engineering Calculations."

\subsection{SUMMARY OF ANALYSIS AND RESULTS}

Conservative assumptions and large margins of safety were employed throughout the analyses. Even so, the study concluded that the potential of a nuclear criticality in the asis configuration of the LLRWDF is incredible, i.e., $<10^{-06}$. The combined probability of a criticality in the LLRWDF (in ELLT 2 and ELLT 3 and in the seven slit trenches of interest) is conservatively estimated to be $0.47 \times 10^{-06}$. Written procedures as well as verbal accounts of actual operations indicate that efforts were made to separate waste containers containing high content of EU. Consideration of such operations contributes to making the probability of a criticality in the LLRWDF much lower than the calculated $0.47 \times 10^{-06}$.

Conservative assumptions employed include the following:

Optimum moderation and reflection within each container.

$>\mathrm{EU}$ at optimum density, i.e., optimum $\mathrm{H}:{ }^{235} \mathrm{U}$ ratio, within the containers.

Optimum geometrical distribution of EU within the containers.

Orderly close-packed arrangement of the drums. 
Neglected the effect of earth (soil) layers between the drums as well as the numerous other "clean" waste materials buried along with the drums.

Violation of WMO procedure requiring separation of EU containers. 5

\subsection{ACKNOWLEDGMENT}

This document summarizes work performed by a number of researchers, physicists, and engineers at Westinghouse Savannah River Company. The author would like to acknowledge the contributions of N.P. Baumann, S.P. Harris, M.J. Murnan, J.H. Weber, T.G. Williamson, and R.S. Wittman.

\subsection{REPORT ORGANIZATION}

The report is divided into the following sections:

1.0 INTRODUCTION

2.0 METHODOLOGY

\subsection{DESCRIPTION OF MODELS}

The purpose and report intent are presented in Section 1.0. An overview of the problem is presented in th is section. Summary of results are also included in this section.

The logical steps followed in assessing the criticality of the LLRWDF sections are outlined in this section. The nuclear criticality safety code, KENO/CG, and other supporting codes are described in Section 2.0.

The two types of waste containers used in the burial of EU in the LLRWDF are described in this section. The various materials employed in the analysis are also described in this section. The Monte Carlo models employed in the criticality calculations and the statistical models used in predicting the probability distribution within and among the containers are described in this section.

\footnotetext{
5 WMO procedure states that "Enriched uranium (Type 20) burials must be separated from all other shipments by a minimum of 3 horizontal feet of earth or 1 B-25 box for engineered low level trench (ELLT) operation when buried" [3].
} 
4.0 ANALYSIS

5.0 SUMMARY OF

RESULTS AND

CONCLUSIONS

6.0 REFERENCES

APPENDIX A
The analyses performed to obtain minimum critical mass loadings for various LLRWDF configurations are presented in this section. Results of the statistical analysis are also presented in this section.

Results of the nuclear criticality safety and statistical calculations are summarized in this section. The probabilities for obtaining a critical mass from the various waste container configurations are summarized in this section.

Documents referenced in this report are listed in this section.

Derivation of the model that calculates the assay uncertainty (total $235 \mathrm{U}$ mass loading) in a configuration of $\boldsymbol{n}$ containers is presented in Appendix A. 


\subsection{METHODOLOGY}

\subsection{INTRODUCTION}

Presented in this section is a general overview of the methodology employed in the nuclear criticality safety assessment of the LLRWDF. An overview of the nuclear criticality safety code and models employed in the analyses is also presented.

\subsection{BASIS}

When more than the minimum critical mass of a fissionable material [5] is contained or allowed to accumulate in a given system, it is necessary to demonstrate that nuclear criticality is incredible. In risk assessment, incredibility is demonstrated by quantifying a maximum probability for its occurrence. For an ongoing process, this probability should be less than one event per million years. For static systems, such as inactive waste tanks and filled burial grounds, this frequency concept does not strictly apply, so an equivalent is required. For this study, the equivalent is taken to be a maximum probability of less than one in a million that criticality will occur over the range of the variables that define the system [7]. Examples of variables defining the system are $235 \mathrm{U}$ mass, neutron poisons, and moderation.

Quantification of a maximum probability is significantly more difficult if transport and relocation of fissile material is included. The analyses documented in this report assume that the 55-gallon drums and B-25 boxes stay intact, and thus the locations of their contents are fixed. The geometry constraints imposed by this assumption leads to ready quantification of an acceptable maximum probability.

The probability of nuclear criticality in the LLRWDF trenches is conservatively calculated by the following steps, (which define the logic of the approach):

Parametric studies are performed until a minimum critical mass for all possible waste container configurations is calculated. The parametric studies allow the determination of optimum moderator and reflector configurations subject to known material and geometrical constraints (assuming uniform composition and distribution of fuel [8]). For example, credit was taken for the carbon steel walls of the containers for all configurations examined. Additionally, for the four-drum system, credit was taken for the fact that low-level solid waste is packaged in 2 liter cardboard cartons (4.25" diameter $\times 8.5^{\prime \prime}$ high) [7]. 
Each system is examined to determine if that system is intrinsically safe at the most optimum distribution within and among components (drums and/or boxes).

If the system is not intrinsically safe, evaluate the probability that the distribution within and among components is such as to allow criticality.

Show that the summed probabilities over all systems is less than one in a million, i.e., the probability for nuclear criticality is incredible.

\subsection{CALCULATIONAL TOOLS \& METHODS}

In determining the probability of nuclear criticality in the LLRWDF, a number of computational codes were employed. This includes nuclear criticality safety codes and codes developed to calculate the volumes formed by intersecting surfaces/bodies. These tools (codes) are described in the following subsections.

\subsubsection{Nuclear Criticality Safety Codes}

There are a vast number of computer codes that are used in the nuclear industry for reactivity (criticality) calculations. These codes differ by the geometry they can model (one-dimensional, e.g., sphere, versus general geometry), the solution method (deterministic, e.g., discrete ordinates, versus probabilistic, e.g., Monte Carlo), and the nuclear data libraries and neutron groups that they employ (two-, four-, sixteen-, ... $n$ groups versus continuous).

In performing the eigenvalue (criticality) calculations documented in this report, modules from the JOSHUA nuclear criticality safety computer codes were used [9]. Modules employed in the criticality calculations are the KOKO, HRXN, ANISN, KENO-IV, and KENO-IV/CG modules. A description of these modules follow:

KOKO is the driver module that controls the execution and data flow among the other JOSHUA modules.

HRXN is a cross-section processor module, which prepares 16-group cross-sections based on the Hansen-Roach library [10]. 
$>$ ANISN is a one-dimensional code that solves the neutron transport equation using the discrete ordinates method. This code was only used to compare its results with the KENO code.

$>$ The KENO-IV/CG code is a three-dimensional Monte Carlo neutron transport code that allows modeling of complicated configurations using combinatorial geometry.

The Monte Carlo method solves the neutron transport equation by following and recording all interactions a neutron experiences from the time its is born (e.g., nuclear fission or $n, 2 n$ reactions) until it disappears by means of leakage or capture. The Monte Carlo method tracks neutron interactions with various nuclei on a random basis that obey certain fundamental laws of probability. Data tracked and tallied in a Monte Carlo calculation include the following:

$>$ production type, e.g., fission, $(n, 2 n),(\alpha, n)$, or $(\gamma, n)$ reactions.

types of interactions, e.g., absorption, scattering, and fission.

$>$ distance traveled between interactions.

energies following interaction.

$>$ time during and between interactions.

$>$ direction of travel.

type of loss, e.g., fission, capture, or leakage.

The Monte Carlo simulations ${ }^{1}$ were performed using neutron cross-section data for 16 energy groups based on the Hansen-Roach library [10]. This cross-section data library has been validated for fissile systems containing 235U fuel [11]. The validation was performed with the ANISN code. The validation process consisted of computing the eigenvalue, i.e., the neutron multiplication factor $\left(K_{\text {eff }}\right)$, for a broad range of critical experiments. $\mathrm{K}_{\text {eff }}$ is defined as the ratio of the neutron production rate to the neutron loss rate. The significance of $\mathrm{K}_{\text {eff }}$ is as follows:

When the production rate equals the loss rate, $\mathrm{K}_{\mathrm{eff}}$ is unity and the system is considered critical.

1 Simulation is the tracking of all interactions a neutron will undergo in the defined system. 
When the production rate is greater than the loss rate, $\mathrm{K}_{\mathrm{eff}}$ is greater than 1.0 and the system is considered supercritical.

When the production rate is less than the loss rate, $\mathrm{K}_{\text {eff }}$ is less than 1.0 and the system is considered subcritical.

A deviation or "bias" that is dependent on the $\mathrm{H}:{ }^{235} \mathrm{U}$ ratio has been derived based on the validation study documented in Reference 11 . The difference between the calculated neutron multiplication factor for a critical system, $\mathrm{K}_{\text {crit, }}$ and $\mathrm{K}=1.00$ is the "bias" in the computation. The bias, denoted by $\sigma_{b}$ in this study, is a function of the $\mathrm{H}:{ }^{235} \mathrm{U}$ ratio, and is obtained by a conservative fit to Figure 1 of Reference 11 for $\mathrm{H}:{ }^{235} \mathrm{U}$ greater than 160 . The following Equation describes the fit as used in this study:

$$
\sigma_{b}\left(H:{ }^{23 s} U\right)=0.11-0.016 \ln \left(H:{ }^{23 s} U\right)
$$

KENO computations have been found to agree closely with results of an ANISN validation study [11] when using the same the 16-group cross section library. Table 2-1 compares ANISN and KENO calculations (using the same cross section library) for critical spheres, covering a range of $\mathrm{H}:{ }^{235} \mathrm{U}$ that is greater than considered for this LLRWDF evaluation [7]. The critical spheres were composed of a homogeneous mixture of $\mathrm{H}_{2} \mathrm{O}$ and ${ }^{235} \mathrm{U}$ surrounded by a $30-\mathrm{cm}$ thick $\mathrm{H}_{2} \mathrm{O}$ shell as a reflector. The $\mathrm{K}_{\text {crit }}$ values are those from Clark's study [11]. The KENO calculations used the same core region radius and material cross sections, but modeled the reflector as a $90 \mathrm{~cm}$ cube of water surrounding the sphere. The cube is considered neutronically equal to the reflector shell in the ANISN calculations. A schematic of the problem geometry is provided in Figure 2-1.

Table 2-1. Comparison Between ANISN and KENO Calculations For Various H:235U Ratios [7]

\begin{tabular}{|c|c|c|c|c|c|}
\hline $\begin{array}{l}\text { H: } 235 \mathrm{U} \\
\text { Ratio }\end{array}$ & $\begin{array}{l}\text { 235U Density } \\
\text { (atoms/bn-cm) }\end{array}$ & $\begin{array}{c}\text { Core Radius } \\
\text { (cm) }\end{array}$ & $\mathbf{K}_{\text {crit }{ }^{1}}$ & KENO $K_{\text {eff }}$ & $\delta k^{2} k^{2}$ \\
\hline 100 & $6.620 \times 10^{-04}$ & 11.275 & 0.9746 & $0.9724 \pm 0.0039$ & $0.23 \%$ \\
\hline 200 & $3.310 \times 10^{-04}$ & 12.324 & 0.9779 & $0.9750 \pm 0.0045$ & $0.30 \%$ \\
\hline 400 & $1.655 \times 10^{-04}$ & 14.448 & 0.9858 & $0.9849 \pm 0.0034$ & $0.09 \%$ \\
\hline 800 & $8.275 \times 10^{-05}$ & 19.361 & 0.9972 & $0.9986 \pm 0.0028$ & $-0.14 \%$ \\
\hline 1200 & $5.517 \times 10^{-05}$ & 26.346 & 1.0044 & $1.0030 \pm 0.0025$ & $0.14 \%$ \\
\hline
\end{tabular}

1 Calculated critical $\mathrm{K}_{\text {eff }}$ using the ANISN code.

2 Deviation of the KENO calculations relative to the ANISN calculations.

Page-8

April 1, 1994
WSRC-TR-94-0127

Westinghouse Savannah River Company 
The results of this comparison study, shown in Table 2-1 and obtained from Reference 7, indicate that ANISN and KENO calculations for the examined $\mathrm{H}:{ }^{235} \mathrm{U}$ range are in excellent agreement. (The difference between the two computational methods ranges from $-0.14 \%$ to $0.30 \%$.) Based on this comparison study, it is concluded that the derived ANISN bias can be used for KENO calculations. These computations then provide $\mathrm{K}_{\text {crit }}$ values as a function of $\mathrm{H}:{ }^{235} \mathrm{U}$ ratio that are effective upper limits for sub-criticality.

An added pad, typically $5 \%$, is frequently subtracted from $K_{\text {crit }}$ to give a $K_{\text {safe, where }}$ $\mathrm{K}_{\text {safe }}$ would be the maximum allowed neutron multiplication factor. In this study, an aoditional "pad" was not implemented due to the following:

The analysis presented in this report is concerned with evaluating the potential of a nuclear criticality in the as-is configuration of the LLRWDF, and does not propose limits nor set bounds for EU burial in B-25 boxes or 55-gallon drums. The purpose of the analysis is to determine the probability criticality and thus comparison of the calculated $\mathrm{K}_{\text {eff }}$ for possible configurations to $\mathrm{K}_{\text {crit }}$ is more appropriate than a comparison to $\mathrm{K}_{\text {safe }}$. Comparison to $\mathrm{K}_{\text {safe }}$ would introduce large margins of conservatism in the probability determinations (critical masses would be much smaller, greatly increasing the probability of occurrence).

Large reactivity margins have been employed in modeling the different containers and container arrangements, as shown in Section 3.0 of this report.

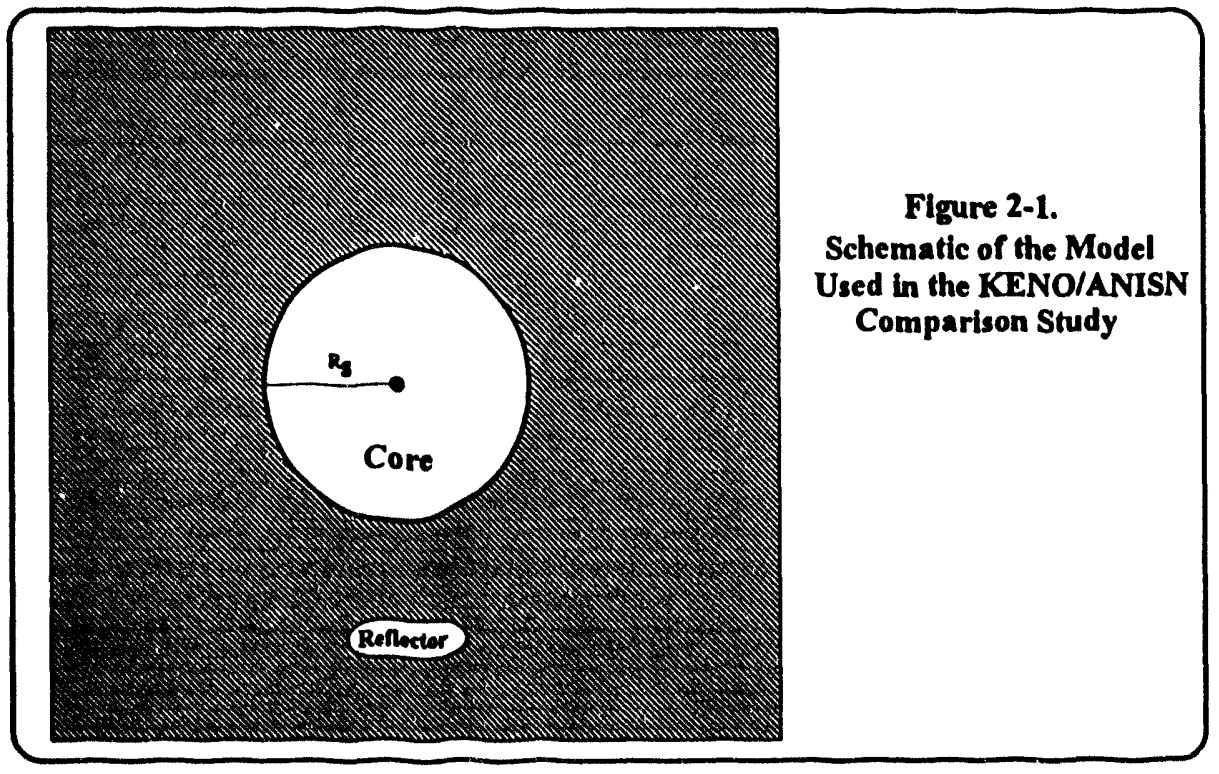




\subsubsection{Volume of Intersecting Bodies}

The analyses presented in this document determined the minimum critical mass of the examined configurations by assuming the fissile region consists of the region formed by the intersection of a sphere(s) with cylinders (55-gallon drums) and/or rectangular parallelepipeds (B-25 boxes) and full spheres and cylinders in each container. These configurations, although unlikely to occur, provide the most neutronically reactive configurations. That is, intersecting spheres normally give lower critical masses than any other configuration. The intersecting spheres can be simply modeled in the KENO/CG code.

The volume (and thus, mass) of the full spheres and cylinders can be easily obtained. However, the volume of the fissile region formed by the intersection of a sphere with the containers can not be obtained easily. Two models were developed in support of this work to calculate the region formed by the intersection of a sphere with the containers and are documented in Reference 12. The models are the following:

sphere intersecting with cylinders (to model the most reactive fissile region inside 55-gallon drums) and

sphere intersecting with rectangular parallelepipeds (to model the most reactive fissile region inside the $\mathrm{B}-25$ boxes). 


\subsection{DESCRIPTION OF MODELS}

\subsection{INTRODUCTION}

The geometry and material used in the construction of the two types of waste containers used in the burial of EU in the trenches and slit trenches of the LLRWDF that are being investigated in this document are described in this section. The various materials employed in the analysis are also described in this section. Additionally, descriptions of the Monte Carlo models employed in the criticality safety assessment and the statistical models used in predicting the probability distribution within- and among the containers are presented in this section.

\subsection{DESCRIPTION OF LLRWDF CONTAINERS}

For the trenches and slit trenches investigated in this study, there are only two types of containers used in the burial of EU. They are B-25 boxes and 55-gallon drums. Table 31 lists the dimensions of the B-25 boxes while a schematic of the B-25 boxes is presented in Figure 3-1. As shown in Figure 3-1, the lid lifting lugs (top) and box lifting lugs (bottom) provide spacing between stacked B-25 boxes, thereby decreasing the neutronic interaction among the boxes. The top lifting lugs of the B-25 boxes are smaller than the box lifting lugs. The function of the box lifting lugs is to provide space for the fingers of the fork-lifts. The height of the box lifting lugs at the bottom of the B-25 boxes provide a minimum vertical separation distance between stacked boxes of 3 inches [7]. The top lifting lugs of the B-25 boxes are smaller than the box lifting lugs. For conservatism, the vertical spacing between stacked boxes is assumed to be 2.5 inches.

The 55-gallon drums employed in the EU burial correspond to the DOT-17C drum [7]. A schematic is presented in Figure 3-2 and relevant dimensions are presented in Table 3-2.

Table 3-1. Dimensions of the B-25 Box "Waste Container" [7]

\begin{tabular}{|l|c|r|}
\hline Length & $72^{\prime \prime}$ & $182.9 \mathrm{~cm}$ \\
\hline Width & $46^{\prime \prime}$ & $116.8 \mathrm{~cm}$ \\
\hline Height . & $47^{\prime \prime}$ & $119.4 \mathrm{~cm}$ \\
\hline Wall Thíckness (14 gauge) & $0.075^{\prime \prime}$ & $0.1905 \mathrm{~cm}$ \\
\hline Box Lifting Lugs & 3 3" & $7.62 \mathrm{~cm}$ \\
\hline Material: & \multicolumn{2}{|c|}{ Carbon Steel } \\
\hline
\end{tabular}




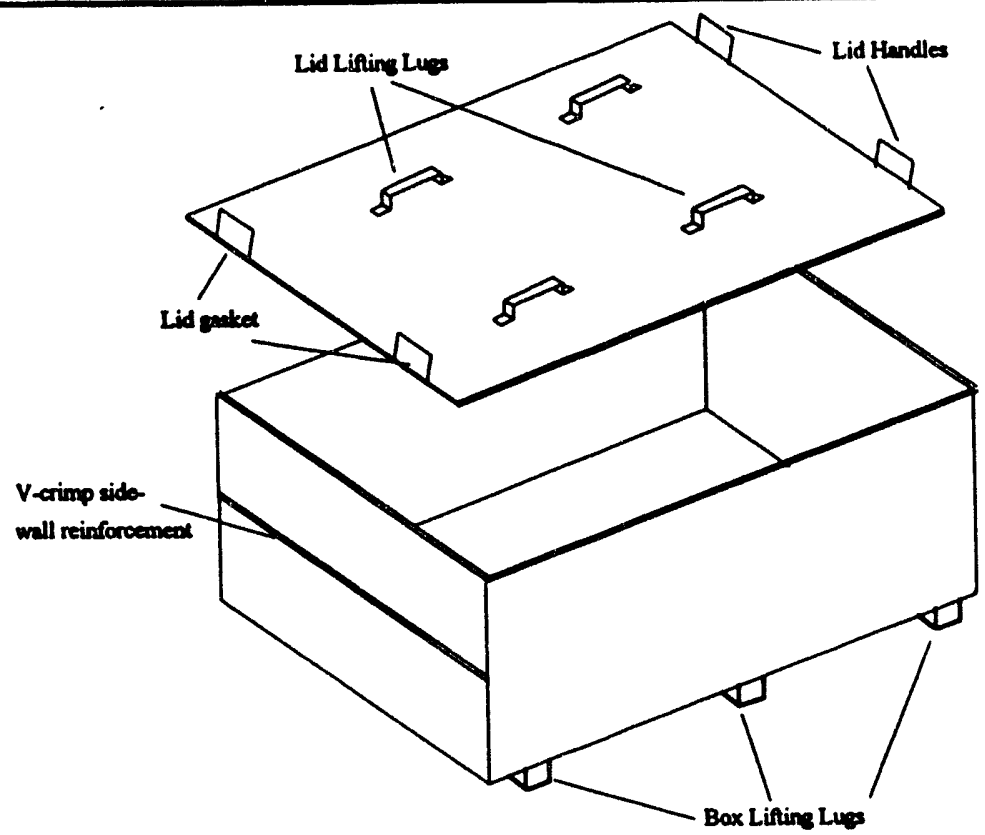

Figure 3-1. Schematic and Dimesnsions of the B-25 Box "Waste Container" [7]

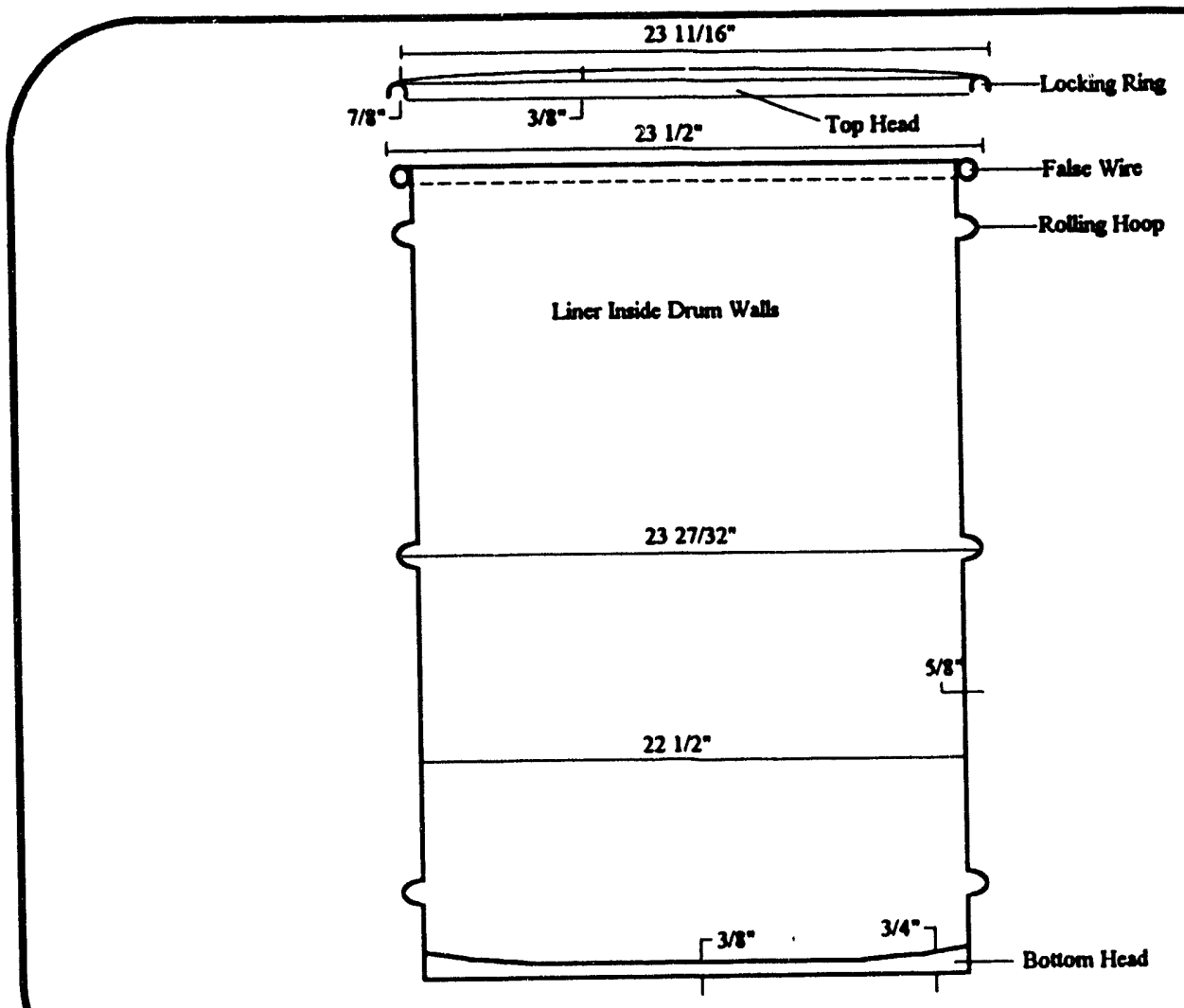

Figure 3-2. Schematic and Dimensions of the 55-Gallon Drums, Type DOT-17C [7] 
Table 3-2. Dimensions of the 55-Gallon Drums [7]

\begin{tabular}{|l|ll|}
\hline \multicolumn{1}{|c|}{ Material: } & \multicolumn{1}{|c|}{ Dimensions (Inches): } & \\
\hline Body \& Heads: & Overall Diameter Over Rolling Hoops & $2327 / 32$ \\
Carbon Steel, 16 Gage & Outside Diameter Over False Wire & $231 / 2$ \\
Nominal 0.0598", 0.1519 cm & Overall Height Over Locking Ring & $3413 / 16$ \\
& Overall Height with Cover Off & $343 / 8$ \\
Locking Ring: & Minimum Convexity of Each Head & $3 / 8$ \\
Carbon Steel, 12 Gage & Rolling Hoops (3) & $5 / 8$ \\
Nominal 0.1046", 0.2657 cm & \multicolumn{2}{|c|}{ a 1/2" false wire. } \\
Inner Drum Liner: & Top Edge of Body metal rolled to form \\
Polyethylene, $0.23 \mathrm{~cm}$ thick & Depth of cover & $7 / 8 "$ \\
\hline
\end{tabular}

\subsection{MODEL DESCRIPTIONS}

\subsubsection{Description of the KENO/CG Models}

The burial of the waste containers in the LLRWDF varies depending on the waste container type. That is, the B-25 boxes are stacked in a close-packed orderly array while the drums are more or less randomly distributed and oriented with soil spacing common between drums. This makes it unlikely that more than two drums will be in close proximity around a common point. The maximum content of any two drums is well below the critical limit. Since random spacing is difficult to quantify, the drums as well as the boxes are assumed to be in an orderly array in the horizontal plane and stacked directly on top of each other in the vertical direction. Random spacing will tend to increase the separation distance between interacting volumes. This assumption of an orderly array allows a configuration which can be modeled in KENO and results in the most neutronically reactive condition. Increasing the separation distances between the drums of a system of four drums was found to cause a decrease in the reactivity (Table 43). The assumption of orderly spacing adds a large but un-quantifiable margin of safety for the drums and for the interacting drums and boxes, but not for the boxes considered alone.

The boxes are assumed to have a minimum separation between successive layers of $2.5^{\prime \prime}$ due to the box lifting lugs attached to the bottom of each B-25 box. No separation is assumed at the sides or ends of the B-25 boxes. The 55-gallon drums are conservatively assumed to have an edge-to-edge spacing of $5 / 8$ " provided by one rolling hoop. No credit is taken for the double separation one would have if both barrels are exactly at the same elevation. The vertical separation between drums is taken to be 1.0 inch. This choice is conservatively derived from the actual separation defined by the convex shape of the top 
and bottom which varies from a minimum 1.5 inches at the outer diameter to a nominal 0.75 inch at the center. For the case of 4,5 , or 6 drum interaction, the outer half of the drum's radius is most important being nearest the center of the intersecting sphere. Over this range, the separation varies from about 1 inch to 1.5 inch.

In modeling the B-25 boxes, the assumption used, which is based on operation practices [3], is that boxes containing ${ }^{235} \mathrm{U}$ are never placed edge-to-edge on the $46^{\prime \prime} \times 47^{\prime \prime}$ faces. It is assumed, however, that four boxes containing ${ }^{235} \mathrm{U}$ can be stacked in a rectangular array $72^{\prime \prime}$ wide by $92^{\prime \prime}$ wide by 96.5 " high (including $2.5^{\prime \prime}$ separation). A schematic of this configuration is shown in Figure 3-3. The uranium is assumed to be contained within the volume defined by the intersection of the box interiors and a sphere centered in the array. The fissile region was assumed to consist of $235 \mathrm{U}$ in full density polyethylene. That is, while maintaining the density of polyethylene at $0.92 \mathrm{~g} / \mathrm{cm}^{3}, 235 \mathrm{U}$ was added to the fissile region. The density of the fissile region would be that of polyethylene $(0.92$ $\mathrm{g} / \mathrm{cm}^{3}$ ) plus the density of ${ }^{235} \mathrm{U}$. The remainder of each box is filled with full density polyethylene $\left(0.92 \mathrm{~g} / \mathrm{cm}^{3}\right)$. As part of this study, the effects of the polyethylene density on the reactivity was examined. The results, shown in Figure 4-1, indicate that full density polyethylene results in the most reactive configuration. The vertical separation between boxes is taken to be filled with wet soil, the composition of which is presented in Table 3-5.

Although it is unlikely that the lifting lugs on the bottom of the B-25 boxes have collapsed or that they made deep indentations in the box immediately below, this case has

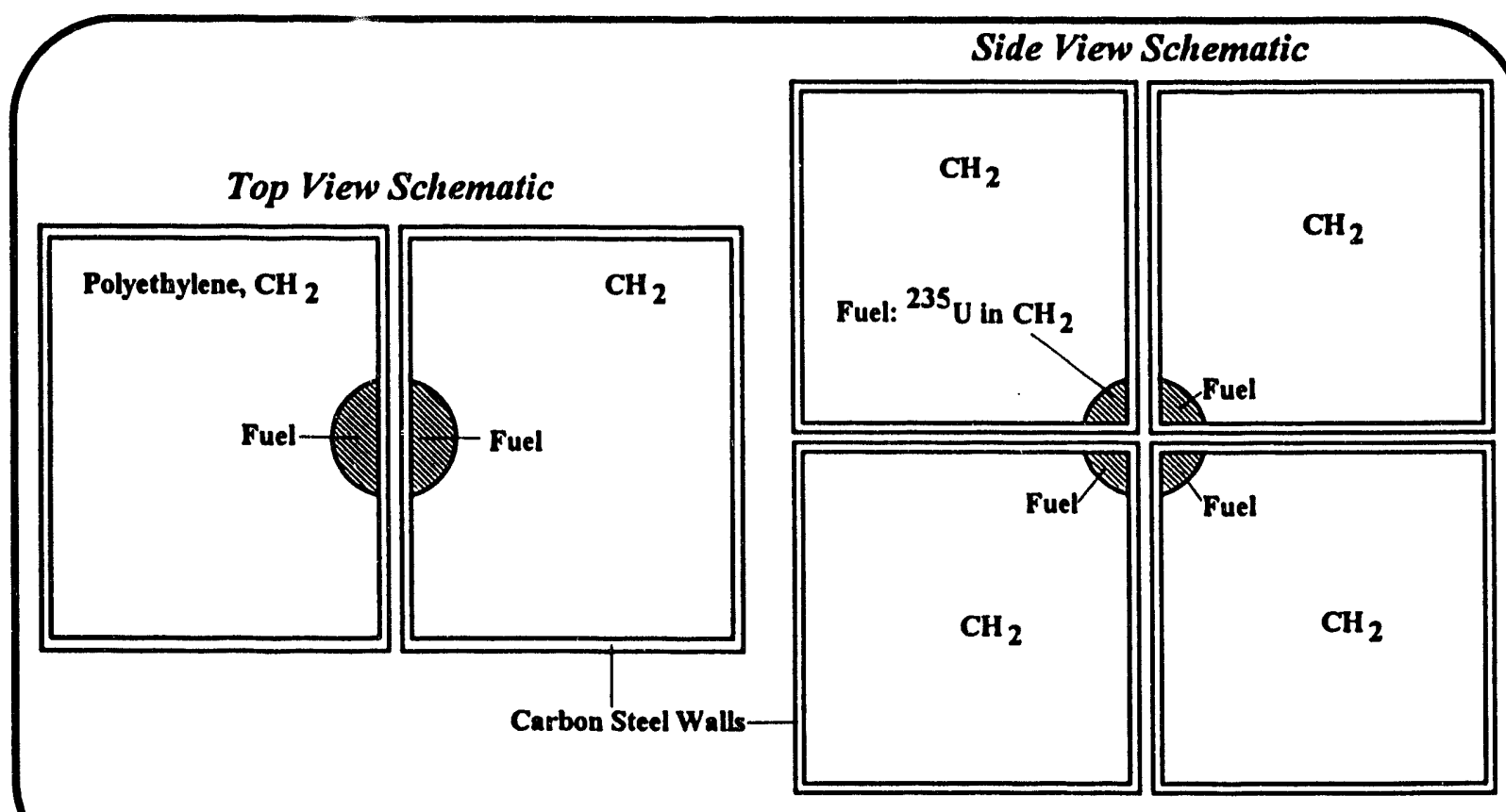

Figure 3-3. Schematic of the Four B-25 Box Configuration Model 
also been evaluated and the results are presented in Table 4-7. The geometry was the same as above except that the vertical clearance between the boxes was reduced to zero.

For the six drum case, the array is taken to be three contacting drums in a triangular array on top of another set of three drums. The uranium is taken to be contained within the volume defined by the intersection of the interior volumes of these drums and a sphere at the center of the array. A side and top view schematic of this configuration is shown in Figure 3-4.

The five drum case is taken to be the six drum case with one drum missing. For the four drum case, the array is taken to be two side-by-side contacting drums on top of two additional drums. The sphere again is at the center of the array, as shown in Figure 3-5.

For the drum/box interaction case, the array is taken to be the bottom of two adjacent drums placed flat against the ends of two adjacent B-25 boxes, as shown in Figure 3-6.

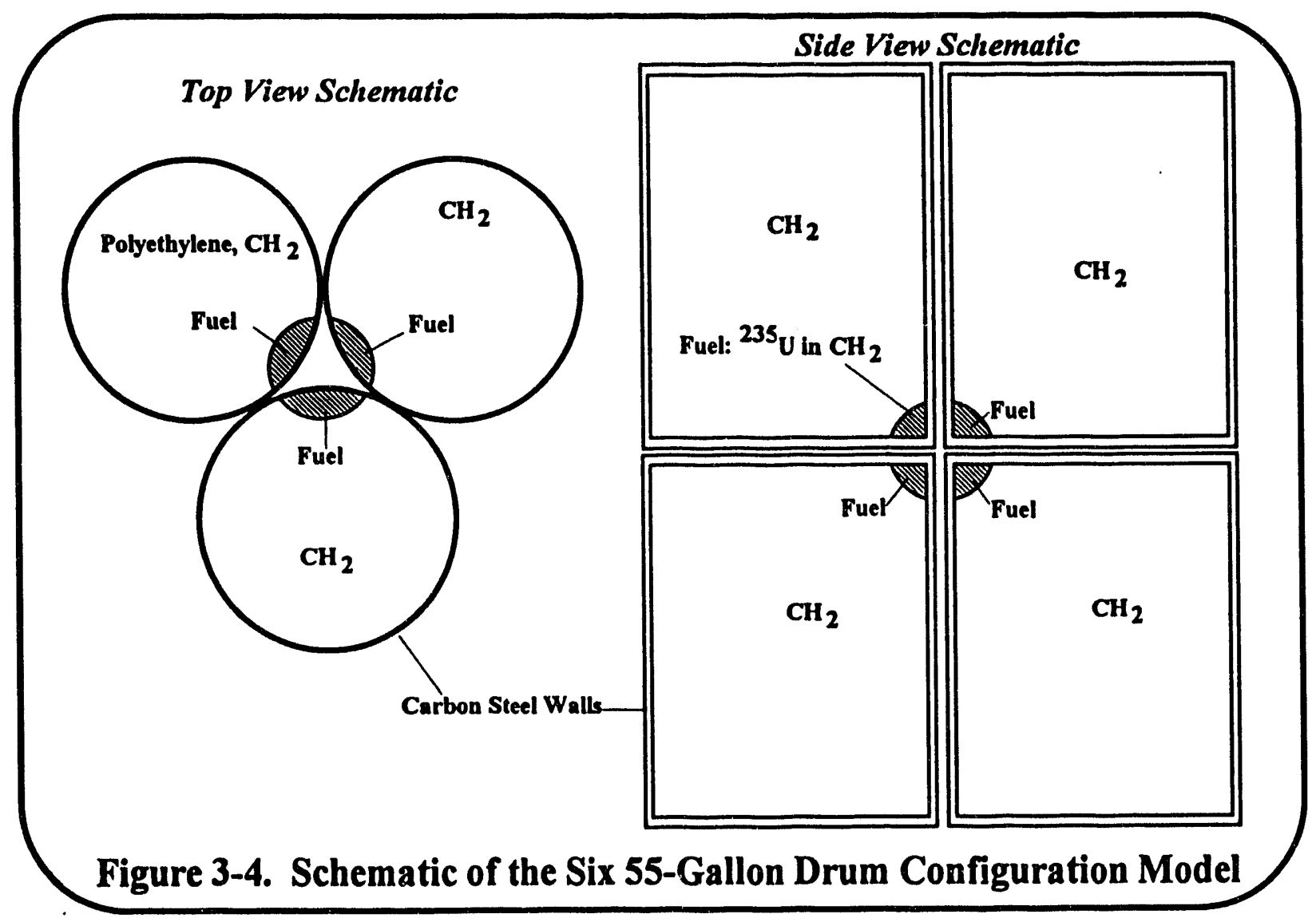




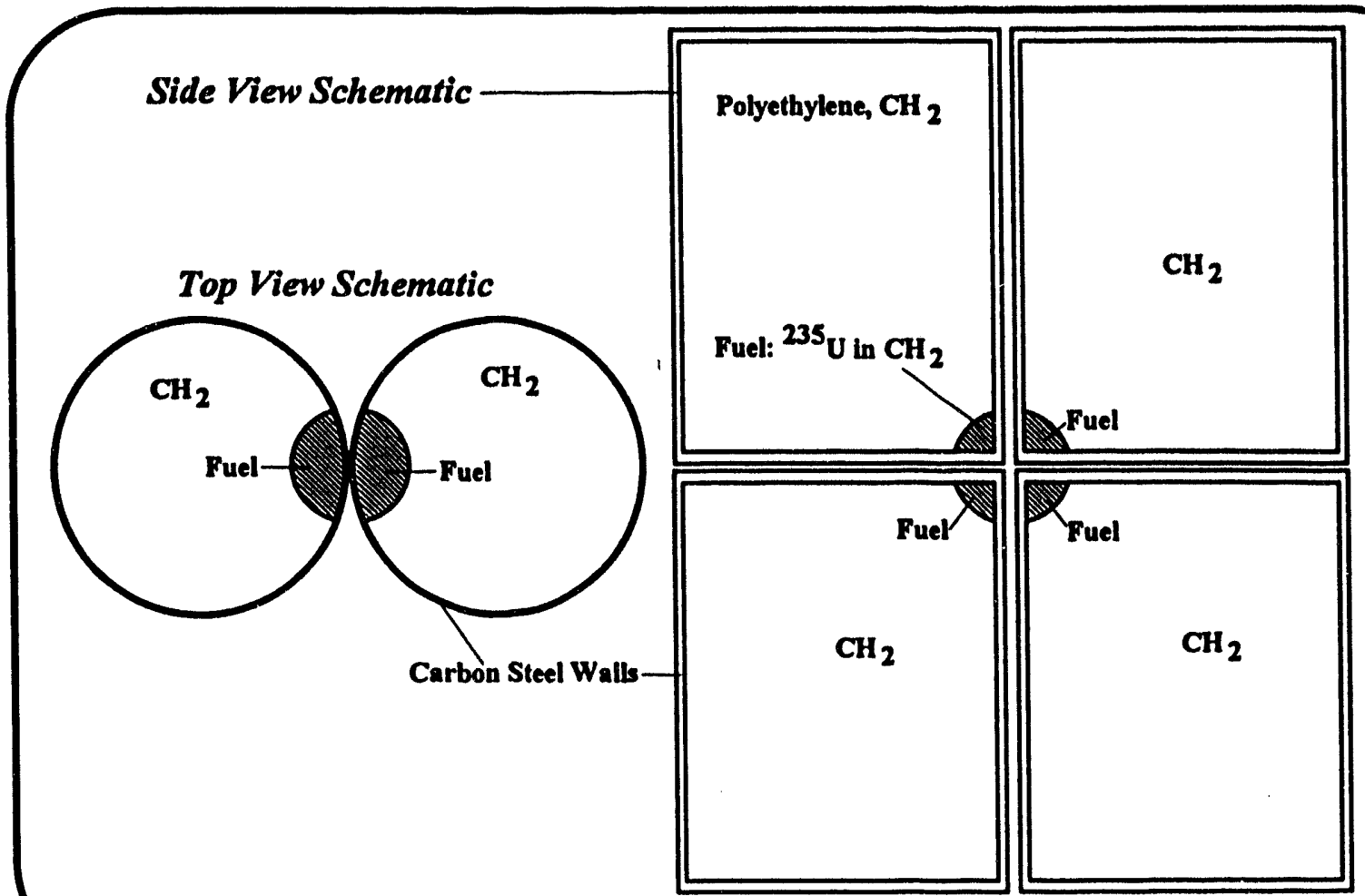

Figure 3-5. Schematic of the Four 55-Gallon Drum Configuration Model

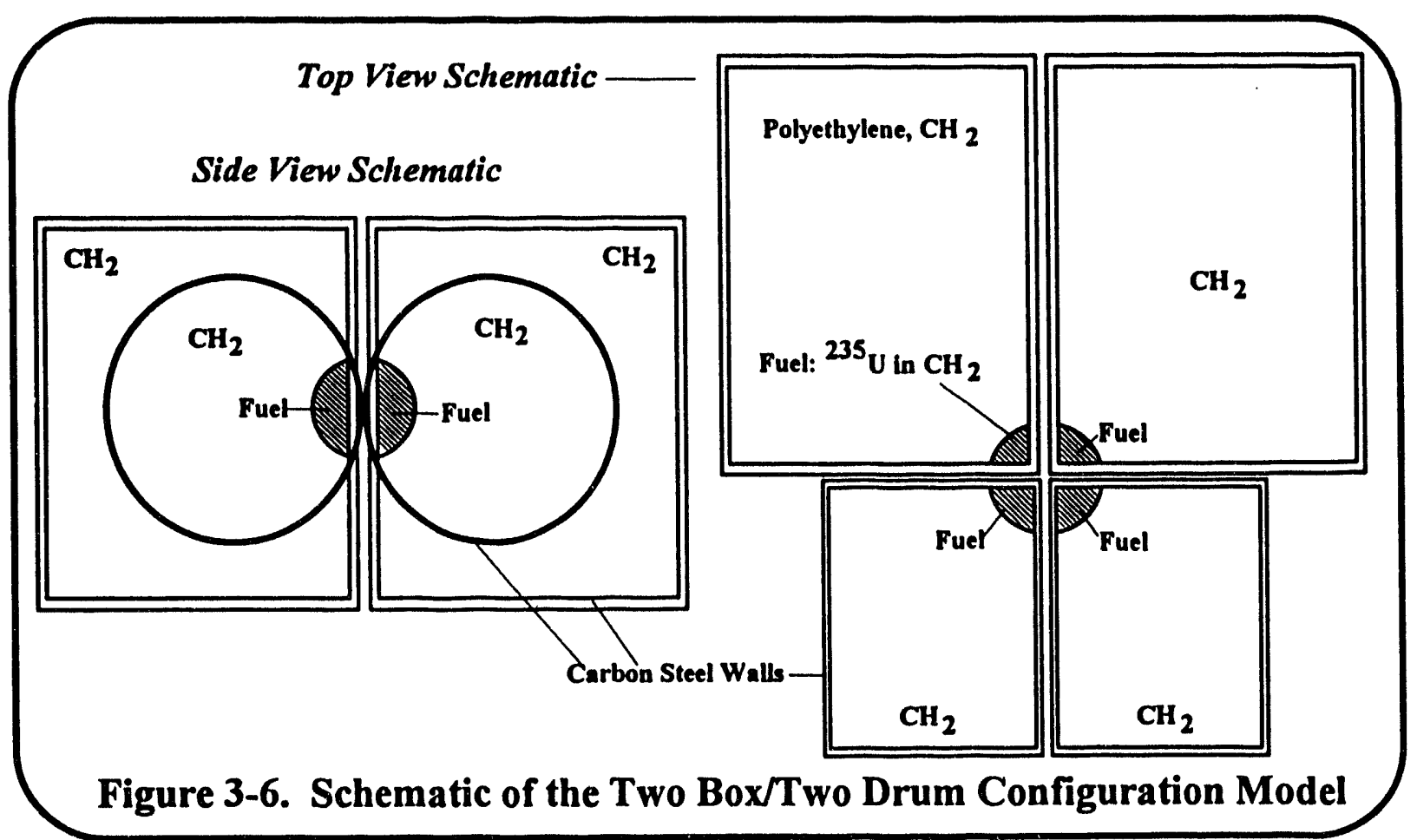


In both the drum and B-25 KENO/CG models, the array is placed in a close fitting rectangular BOX. The region inside this BOX and outside the drums or B-25 containers is filled with wet soil. The region outside the BOX is a reflector with the composition of soil, wet soil, or concrete. Concrete was employed for comparison purposes only. The composition of these materials is listed in Table 3-5.

\subsubsection{Description of Materials Employed in the Analysis}

Throughout the analysis, five different distinct regions were modeled: fuel (fissile) region, internal reflector region, container walls region, intermediate reflector region, and external reflector region. These regions along with the various materials employed in them are described as follows:

$>$ Fissile Region. The fissile region consists of a homogeneous mixture of 235U with polyethylene. That is, while maintaining the density of polyethylene at $0.92 \mathrm{~g} / \mathrm{cm}^{3}, 235 \mathrm{U}$ was added to the fissile region. The density of the fissile region would be that of polyethylene $\left(0.92 \mathrm{~g} / \mathrm{cm}^{3}\right)$ plus the density of ${ }^{235} \mathrm{U}$. The density of the ${ }^{235} \mathrm{U}$ was varied until the optimum moderation $\left(\mathrm{H}:{ }^{235} \mathrm{U}\right)$ for each configuration was obtained. An embedded conservative assumption is that the fuel is $100 \% 235 \mathrm{U}$. The naval fuels waste containing EU is $\approx 97 \% 235 \mathrm{U}$ [3].

Internal Reflector. This region consists of the remaining region inside the drums or boxes. Full density polyethylene was assumed and was found to be the most reactive.

Containers' Wall Region. The container walls were modeled as carbon steel.

DIntermediate Reflector Region. This region consists of the region between the interacting containers. The effects of various intermediate reflector materials on the reactivity were examined: dry soil, wet soil, pure water, and concrete.

External Reflector Regions. This region surrounds the systems/configuration examined. As with the intermediate $r$ rflector region, the effects of various materials and thicknesses of these materials on the reactivity were examined: dry soil, wet soil, pure water, and concrete. 
Although the 55-gallon drums employ a $0.23 \mathrm{~cm}$ thick polyethylene liner, this liner was not explicitly modeled. While maintaining the drums for a system of four drums in contact, the separation distance of the fissile regions from the interior walls of each drum was varied. The results indicated that the reactivity decreases as this separation distance increases. Since the remaining region inside the drums (outside the fissile region) is modeled with full density polyethylene, then increasing the separation distance between the fissile region and the drum's interior wall implicitly models the polyethylene liner. The analysis concluded that modeling the polyethylene liner reduces the reactivity. This is due to an increase in the over-all separation distance between the interacting regions, which in turn reduces the neutronic coupling among the fissile regions of the different drums.

Listed in Table 3-3 are the various materials utilized in the five distinct regions. The compositions of these materials (with the exception of $235 \mathrm{U}$ in water, $235 \mathrm{U}$ in polyethylene, and Savannah River Site soil) are listed in Table 3-4. The soil composition, which is shown in Table 3-5, is typical soil composition found at the Savannah River Site (SRS) [7]. In modeling the soil, the $5.11 \%$ organic matter was conservatively assumed to be polyethylene $\left(\mathrm{CH}_{2}\right)$, an effective neutron moderator. Table 3-5 indicates that phosphorus $(\mathrm{P})$ has been omitted from the description. This was done since the neutron cross section library utilized in the analysis does not provide data for phosphorus. However, due to the relatively large absorption-to-scattering ratio $(\approx 0.04)$ for phosphorus compared with other soil elements, e.g., 0.009 for hydrogen, the effect of neglecting phosphorus is conservative.

Also shown in Table 3-5 is the composition of wet soil. The difference in the composition of the soil and wet soil is the hydrogen and oxygen content, i.e., $\mathrm{H}_{2} \mathrm{O}$ was

Table 3-3. List of Materials Employed in the Five Regions of All Interacting Systems

\begin{tabular}{|c|c|c|c|c|c|}
\hline & $\begin{array}{c}\text { Fissile } \\
\text { Region }\end{array}$ & $\begin{array}{c}\text { Internal } \\
\text { Reflector }\end{array}$ & $\begin{array}{c}\text { Container's } \\
\text { Walls }\end{array}$ & $\begin{array}{c}\text { Intermediate } \\
\text { Reflector }\end{array}$ & $\begin{array}{c}\text { Exterior } \\
\text { Reflector }\end{array}$ \\
\hline 235U in Polyethylene & $\mathrm{X}$ & & & & \\
\hline 235U in H2O & $\mathrm{X}$ & & & & \\
\hline Carbon-Steel & & & $\mathrm{X}$ & & \\
\hline Soil & & $\mathrm{X}$ & & $\mathrm{X}$ & $\mathrm{X}$ \\
\hline Wet Soil & & $\mathrm{X}$ & & $\mathrm{X}$ & $\mathrm{X}$ \\
\hline Oak Ridge Concrete & & $\mathrm{X}$ & & $\mathrm{X}$ & $\mathrm{X}$ \\
\hline & & $\mathrm{X}$ & & $\mathrm{X}$ & $\mathrm{X}$ \\
\hline Polyethylene & & $\mathrm{X}$ & & $\mathrm{X}$ & $\mathrm{X}$ \\
\hline
\end{tabular}


Table 3-4. Composition of Selected Materials Employed in this Study

\begin{tabular}{|c|c|c|c|c|}
\hline "্যে & \multicolumn{4}{|c|}{ Atom Density (a oms/barn-cm) } \\
\hline Dlement: & $\mathbf{H}_{2} \mathbf{O}$ & Polyethylene & Concretel & Carbon Steel2 \\
\hline Si & & & $1.70 \times 10^{-3}$ & \\
\hline 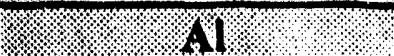 & & & $5.56 \times 10^{-4}$ & \\
\hline $1.87 .8 \mathrm{Fe}$ & & & $1.93 \times 10^{-4}$ & $8.35 \times 10^{-2}$ \\
\hline $19.8 \mathrm{a}$ & & & $1.11 \times 10^{-2}$ & \\
\hline $\mathrm{Mg}$ & & & $1.86 \times 10^{-3}$ & \\
\hline $7 . \bar{K}$ & & & $4.03 \times 10^{-5}$ & \\
\hline . & $6.67 \times 10^{-2}$ & $7.94 \times 10^{-2}$ & $8.50 \times 10^{-3}$ & \\
\hline $7=0$ & $3.35 \times 10^{-2}$ & & $3.55 \times 10^{-2}$ & \\
\hline C. & & $3.97 \times 10^{-2}$ & $2.02 \times 10^{-2}$ & $3.92 \times 10^{-3}$ \\
\hline : & & & & \\
\hline Q, Density $/ \mathrm{cm}^{3}$ & 0.998 & 0.925 & 2.299 & 7.821 \\
\hline
\end{tabular}

1 Oak Ridge concrete, which is a standard HRXN mixture [9].

2 A standard HRXN mixture [9].

added to the soil to arrive at the wet soil composition. The amount of $\mathrm{H}_{2} \mathrm{O}$ added was determined as follows:

From the theoretical density and weight percent of the constituent and from the density of the soil of $1.6 \mathrm{grams} / \mathrm{cm}^{3}$ (shown in Table 3-5), the theoretical volume fraction that constituent would occupy is calculated using the following:

$$
V_{c}^{\prime}=W_{c} \rho_{\text {soul }} / \rho_{c}
$$

where

$V_{e}^{f:} \quad$ theoretical volume fraction of the constituent;

$W_{c}: \quad$ weight fraction of the constituent in the soil;

$\rho_{\text {cail }}:$ density of the soil $\left(1.6 \mathrm{grams} / \mathrm{cm}^{3}\right)$; and

$\rho_{c}: \quad$ theoretical density of the constituent. 
Table 3-5. Composition of the SRS Soil Employed in This Study [7]

\begin{tabular}{|c|c|c|c|c|}
\hline \multirow{2}{*}{ 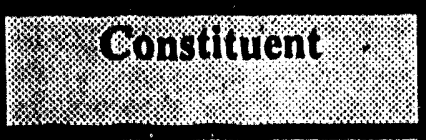 } & \multirow{2}{*}{$\begin{array}{l}\text { Weight } \\
\text { Percent }\end{array}$} & \multicolumn{3}{|c|}{ Atom Density (atoms/barn-cm) } \\
\hline & & Element: & Soil & Wet Soil \\
\hline $\mathrm{SIO}_{3}$ & 37.5 & SI & $6.0136 \times 10^{-3}$ & $6.0136 \times 10^{-3}$ \\
\hline$=\mathrm{N}_{2} \mathrm{O}_{3}$ & 36.39 & 21 & $6.8772 \times 10^{-3}$ & $6.8772 \times 10^{-3}$ \\
\hline $1.7 \mathrm{Fe}_{2} \mathrm{O}_{3}$ & 10.47 & $\mathrm{Fe}$ & $1.2633 \times 10^{-3}$ & $1.2633 \times 10^{-3}$ \\
\hline $1.9 \mathrm{CaO}$ & 0.21 & $\mathrm{Ca}$ & $3.6083 \times 10^{-5}$ & $3.6083 \times 10^{-5}$ \\
\hline $1 \mathrm{MgO}$ & $\overline{0.44}$ & Mg & $1.0519 \times 10^{-4}$ & $1.0519 \times 10^{-4}$ \\
\hline $\mathrm{K}_{2} \mathrm{O}$ & 0.71 & $\mathbf{K}$ & $1.4525 \times 10^{-4}$ & $1.4525 \times 10^{-4}$ \\
\hline$\because 7 \mathrm{Na}_{2} \mathrm{O}$ & 0.05 & $\overline{\mathrm{Na}}$ & $1.5546 \times 10^{-5}$ & $1.5546 \times 10^{-5}$ \\
\hline $\mathrm{TiO}_{2}$ & $\overline{0.94}$ & $\pi$ & $1.1339 \times 10^{-4}$ & $1.1339 \times 10^{-4}$ \\
\hline $\mathrm{P}_{2} \mathrm{O}_{5}$ & 0.21 & $\mathbf{S}$ & $1.5644 \times 10^{-5}$ & $1.5644 \times 10^{-5}$ \\
\hline$=\mathrm{SO}_{3}$ & 0.13 & Mn & $1.6299 \times 10^{-5}$ & $1.6299 \times 10^{-5}$ \\
\hline Mno & 0.12 & H & $2.1577 \times 10^{-2}$ & $3.8243 \times 10^{-2}$ \\
\hline Organic Matter & 5.11 & 0 & $3.2095 \times 10^{-2}$ & $4.0428 \times 10^{-2}$ \\
\hline Combined Water & 13.6 & C & $3.5146 \times 10^{-3}$ & $3.5146 \times 10^{-3}$ \\
\hline & 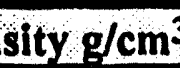 & & 1.69 & 1.94 \\
\hline
\end{tabular}

1 The weight percents are those for soil, i.e., not wet soil. The weight percents of the constituents add to $105.88 \%$. The original reference, which was "The Nature and Properties of Soils," was also found to contain the same weight percents provided above. As part of this study, increasing the density of the soil was found to increase the reactivity. For example, increasing the density of the soil from $1.6 \mathrm{~g} / \mathrm{cm}^{3}$ to $2.5 \mathrm{~g} / \mathrm{cm}^{3}$ caused a $1.2 \% \delta / \mathrm{k}$ increase. Therefore, using the $105.88 \%$ values (i.e., density of $1.69 \mathrm{~g} / \mathrm{cm}^{3}$ ) was conservative.

$>$ The total volume fraction was obtained by summing Equation (3-1) over all constituents, and was found to be 0.747 .

The wet soil composition was then obtained by filling the residual 0.253 of the theoretical volume with $\mathrm{H}_{2} \mathrm{O}$.

\subsubsection{Description of the Statistical Models}

The probability distributions within the containers (55-gallon drums or B-25 boxes) and the probability for juxtapositioning the individual drums are both utilized in the statistical model. The internal probability was derived from the following model:

- Each drum or box is considered to be made up of uniform cells which are small boxes for the B-25 boxes and pie-shaped sectors for the drums. 
- All of the $235 \mathrm{U}$ is assumed to be contained in one compact optimum volume (sphere, intersecting sphere, or cylinder) defined by the configuration being examined, e.g., four B-25 box model. The $235 \mathrm{U}$ content was that for the critical mass limit. The H:235U ratio was that resulting in the highest reactivity.

- The value of $\mathrm{K}_{\text {eff }}$ is computed for the intersecting sphere with uniform ${ }^{235} \mathrm{U}$ in each container. This establishes a reference $\mathrm{K}_{\text {eff }}$.

(1) The value of $\mathrm{K}_{\text {eff }}$ is computed for the same configuration but with the 235U removed from one drum or box.

- The value of $\mathrm{K}_{\text {eff }}$ is computed for the same configuration except that the drum with the $235 \mathrm{U}$ removed now has an optimally moderated sphere (with the same amount of $235 \mathrm{U}$ that was present in the original drum) in the cell closest to that from which the ${ }^{235} \mathrm{U}$ had been removed.

- It is determined that the difference in $K_{\text {eff }}$ between steps 4 and 5 is within the individual uncertainties and that these uncertainties are small compared to the difference between step 3 and step 4. If this is not the case, the cell size is increased (number of cells within the containers are decreased) and step 5 is repeated until this criteria is satisfied, i.e., neutronic (nuclear) decoupling is obtained.

For the drum, a division of the drum into 4 vertical levels with quadrants at each level satisfied the above conditions. This gives a probability of $1 / 16$ per drum that the $235 \mathrm{U}$ will be in the cell nearest the center of the 4 or 6 drum array. The probability for the 235 $U$ in all 6 drums to be in the nearest cell is then $5.96 \times 10^{-08}, 5$ drums is $9.54 \times 10^{-07}$, and 4 drums is $1.526 \times 10^{-05}$. The probability for a given drum configuration is calculated using the following:

$$
P_{n}=1 / 16^{n}
$$

where $n$ is the number of drums in the system, i.e., 4,5 , or 6 and $P_{n}$ is the internal distribution probability for that system.

For the boxes, the intersecting sphere was placed at the center of four boxes, as shown in Figure 3-6. A cell size $1 / 5$ the height and breadth and 1/7 the width was found to satisfy the conditions for nuclear uncoupling. Utilizing this internal sub-division results in an internal probability distribution per box of $1 / 175$ that the $235 \mathrm{U}$ will be in the cell required 
for nuclear interaction. Results of the KENO calculations for the drums and boxes are presented in Table 4-5.

The assumption of equal probability among the cells is believed to be conservative or neutral for the following:

If the non-uniformity is due to gravitational compression, the resultant gap would be at the top. This would uncouple successive vertical layers, reduce the number of interacting units by a factor of two, and thus eliminate all possibility of criticality. The same argument applies to a preferential placement of fissile material at the top or bottom of the B-25 boxes. The only preferred placement that could increase the interaction probability is the deliberate loading of the drums such that nearly all of the fissile material is in one corner of every drum. It is known that this was not done.

To complete the statistical evaluation it is necessary to conservatively evaluate the expectation value for 4,5 , or 6 drums to be in a close-packed array and contain a critical mass. The expectation value is closely related to the probability. Numerically, it is equal to the sum of the probability for at least one combination, plus the probability for at least two combinations, ...etc. If the probability for at least one combination is low, then the probability for two or more is negligible and the expectation value becomes equal to the probability. The following procedure was used to evaluate the expectation values, where the expectation value is that for the summed content of six drums exceeding the critical mass limit. For simplification, only the six drum case is discussed. The four and five drum cases follow mutates mutandis.

- A section of trench is selected in which the contents of six or fewer drums sum to more than the computed mass limit. The boundary of each region is defined by an interval 30 feet wide in which there are no six-drum combinations with enough $235 \mathrm{U}$ to sum to the limiting value, including a two-sigma uncertainty.

2. A tabulation of individual ${ }^{235} \mathrm{U}$ contents is made of all drums within this interval, including those devoid of ${ }^{235} \mathrm{U}$. The assay of each drum is obtained from COmputerized Burial Record Analysis (COBRA) data files [13].

- It is assumed that the drums from one active interval are randomly selected. Units of two stacked drums are then sequentially arranged in a close packed two-tier array so that at each step a new six-drum array is 
formed, as shown in Figure 3-7. With this arrangement, the $235 \mathrm{U}$ summed over the last six drums gives the total for that six-drum array. If the sum exceeds the allowed mass, one has a possible critical configuration. (For the five-drum case the drums are added one-by-one rather than in pairs. For the four-drum case, a separate sum is made over each adjacent pair, i.e., in Figure 3-7, drums 5 and 6 would be summed with drums 1 and 2 as well as drums 3 and 4).

- A utility code randomly sorts the order of the drums and then checks to see how often a sequential six drums added two at a time sum to more than the allowed mass [7]. The process is repeated a thousand or more times in order to obtain the average expectation value.

The procedure for the interaction of drums with boxes is similar. It is conservatively assumed that any combination of two drums will be in the optimum geometry, i.e., centered and flush against the face of two boxes as in Figure 3-6. A separate listing is made of all of the $235 \mathrm{U}$ bearing drums in the vicinity of the boxes and of all the $235 \mathrm{U}$ bearing boxes in the vicinity of the drums. For the statistical evaluation, the drums are arranged in random sequence. Pairs are defined in sequence. The $235 \mathrm{U}$ contents of each successive pair of drums in turn has added to it the contents of two randomly selected boxes. (The list of boxes from which the two were selected included all $235 \mathrm{U}$ bearing boxes in the vicinity. The dilution by "empty" boxes was not included.) The summed contents of the two drums and two boxes is then checked to see if the minimum critical mass, including a two sigma uncertainty, is exceeded. The expectation value for the two drum/ two box combination is then obtained by repeating the process numerous times to obtain the average number of times per sequence that the minimum critical mass is exceeded. A similar evaluation has been independently made for the stacked boxes. This evaluation derived probabilities rather than expectation values, but since the derived probabilities were small they are numerically equivalent.

\subsubsection{Assay Uncertainties}

Certain scrap containers (2-liter containers) are reclassified waste sent to the burial ground (LLRWDF) inside a 55-gallon drum or B-25 Box. The estimated uncertainties for the Low Density Scrap Assay system used in measuring the $235 \mathrm{U}$ content in the 2-liter scrap containers are a $10 \%$ random error and a $2 \%$ systematic error [14]. These percent errors are assigned a $95 \%$ (two- $\sigma$ ) confidence level [14]. Then the one- $\sigma$ values are $5 \%$ and $1 \%$ for the random and systematic errors, respectively. 


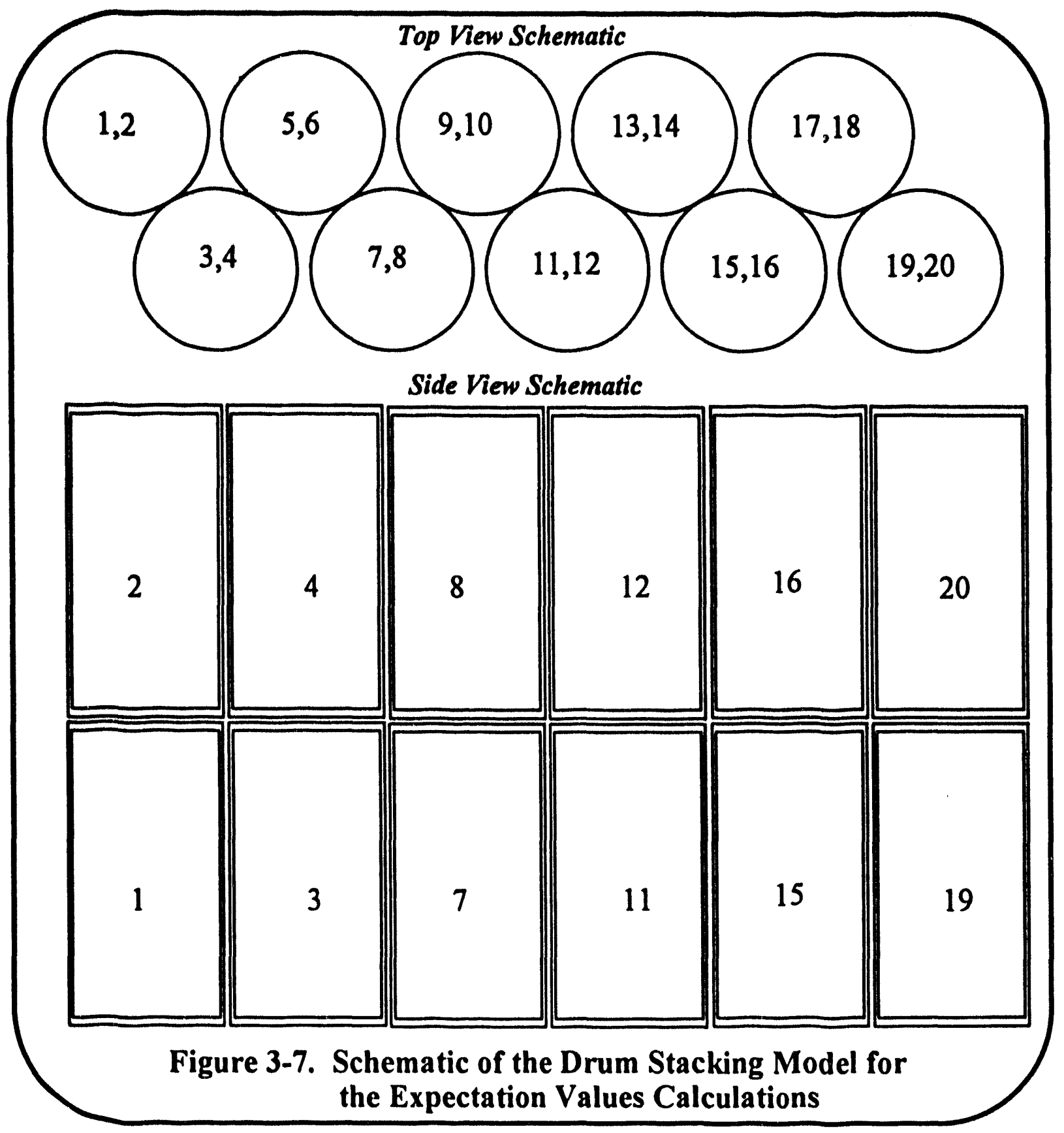

The original study employed the following Equation for calculating the assay uncertainty in a given configuration [7]:

$$
\left.E r r\right|_{n}=\sigma_{s}+\frac{\sigma_{r}}{\sqrt{n}}
$$

where: 
Err $L_{\text {: }}$ overall uncertainty in the mass loading of $235 \mathrm{U}$ for the configuration with $n$ containers;

$\sigma_{\sigma}: \quad$ systematic error of the Low Density Scrap Assay system (2\%); and

$\sigma_{\text {r }}: \quad$ random error (10\%).

Equation (3-3) was conservatively employed in the original analysis [7]. A more accurate model for estimating the assay uncertainty in a given configuration is derived in Appendix A and presented as Equation (A-9). However, applying Equation (3-3) to the systems of 4,5 , and 6 containers result in a $2 \sigma_{Z}$ uncertainty of $7 \%, \approx 6.5 \%$, and $\approx 6.1 \%$, respectively, which are higher uncertainty levels than calculated by use of Equation (A9). Employing Equation (3-3) rather than Equation (A-9) is conservative since it results in assigning higher uncertainty levels in the analysis and thereby over estimating the probability of criticality in the LLRWDF.

Use of the $2 \sigma_{\boldsymbol{Z}}$ levels calculated by Equation (3-3) in the analysis is as follows:

- A sub-critical mass loading (under optimum neutronic conditions) for each examined configuration is determined using the methodology described in Section 2.0.

(2) To account for the assay uncertainty, the selected maximum sub-critical mass loading are reduced by the percentages calculated using Equation (3-3) to arrive at the $95 \%$ confidence level, i.e., employing $2 \sigma_{Z}$ uncertainty.

3 The probability for obtaining configurations exceeding the sub-critical mass loading value calculated in step 2 above for each trench area is then calculated using the methodology described in Section 3.3.3. 
THIS PAGE INTENTIONALLY LEFT BLANK 


\subsection{ANALYSIS}

\subsection{INTRODUCTION}

The analyses performed to obtain minimum critical mass loadings for various LLRWDF configurations are presented in this section. In obtaining the optimum neutronic conditions (reactivity), the LLRWDF configurations are modeled to minimize neutron losses (via absorption and leakage) and amplify neutron production. This implies obtaining the most neutronically reactive configurations in terms of geometric distribution, moderation, internal and external reflectors, and separation distances between containers. Results of the statistical analysis are also presented in this section.

\subsection{REACTIVITY CALCULATIONS AND ANALYSIS}

The geometry models of configurations examined in the sections that follow are set up in combinatorial units, which are regular solids such as spheres, right parallelepipeds, and right circular cylinders. The combinatorial configuration is enclosed in a tight fitting cuboid. Reflector slabs may also be placed outside this cuboid or boundary conditions equivalent to certain standard built in reflectors may be used.

For the parametric studies, the following terms are defined:

$>$ "containers:" 55-gallon drums and B-25 boxes.

"fuel region:" a homogeneous mixture of ${ }^{235} \mathrm{U}$ in polyethylene.

$>$ "internal reflector:" region outside the fissile region but inside the containers.

$>$ "intermediate reflector:" region inside the cuboid and outside the containers.

$>$ "external reflector:" region outside the cuboid.

\subsubsection{U Moderation}

The optimum $235 \mathrm{U}$ density in polyethylene for a given configuration is obtained by varying the volume of the fissile region and the ${ }^{235} \mathrm{U}$ density in the fissile region while maintaining the mass loading at a fixed amount. The fissile region was assumed to consist of a mixture of ${ }^{235} \mathrm{U}$ in full density polyethylene. That is, while maintaining the density of polyethylene at $0.92 \mathrm{~g} / \mathrm{cm}^{3}$, the $235 \mathrm{U}$ density was varied while varying the volume of the entire fissile region so that the mass loading of $235 \mathrm{U}$ is fixed. The 
configuration with the highest reactivity (bias, using Equation (2-1), is added to the calculated $\mathrm{K}_{\text {eff }}$ is then chosen. For example, shown in Figure 4-1 is a plot of $\mathrm{K}_{\text {eff; }}$ expected value of $\mathrm{K}_{\text {eff }}$ as obtained from the $\mathrm{KENO} / \mathrm{CG}$ code, as a function of the ${ }^{235} \mathrm{U}$ density in polyethylene. The data shown in Figure 4-1 correspond to the following configuration:

$>$ a 4-drum configuration in a square pitch;

$>$ wet soil as the external moderator and reflector material;

$>80 \mathrm{~cm}$ of reflector;

$>$ side-by-side drum separation distance of $5 / 8$ " $(\approx 1.59 \mathrm{~cm})$;

$>$ head-to-head drum separation distance of $1 "$ " $(2.54 \mathrm{~cm})$;

$>$ polyethylene at $0.92 \mathrm{~g} / \mathrm{cm}^{3}$ as the drum's internal reflector material

$>{ }^{235} \mathrm{U}$ mass loading of 300 grams/drum (1,200 grams total); and

$>$ fuel region formed by the intersection of a sphere, which is centered between the drums, with the drums.

Listings for the KENO/CG and HRXN input files for the configuration listed above are provided in Reference 7.

The results of Figure 4-1 indicate that, when the statistical uncertainty in the calculated $\mathrm{K}_{\text {eff }}$ is accounted for, $\mathrm{K}_{\text {eff }}$ is approximately flat for the $235 \mathrm{U}$ density range of $\approx 80$ to $\approx 120$ gram/liter. For further analyses involving the four-drum configuration with intersecting

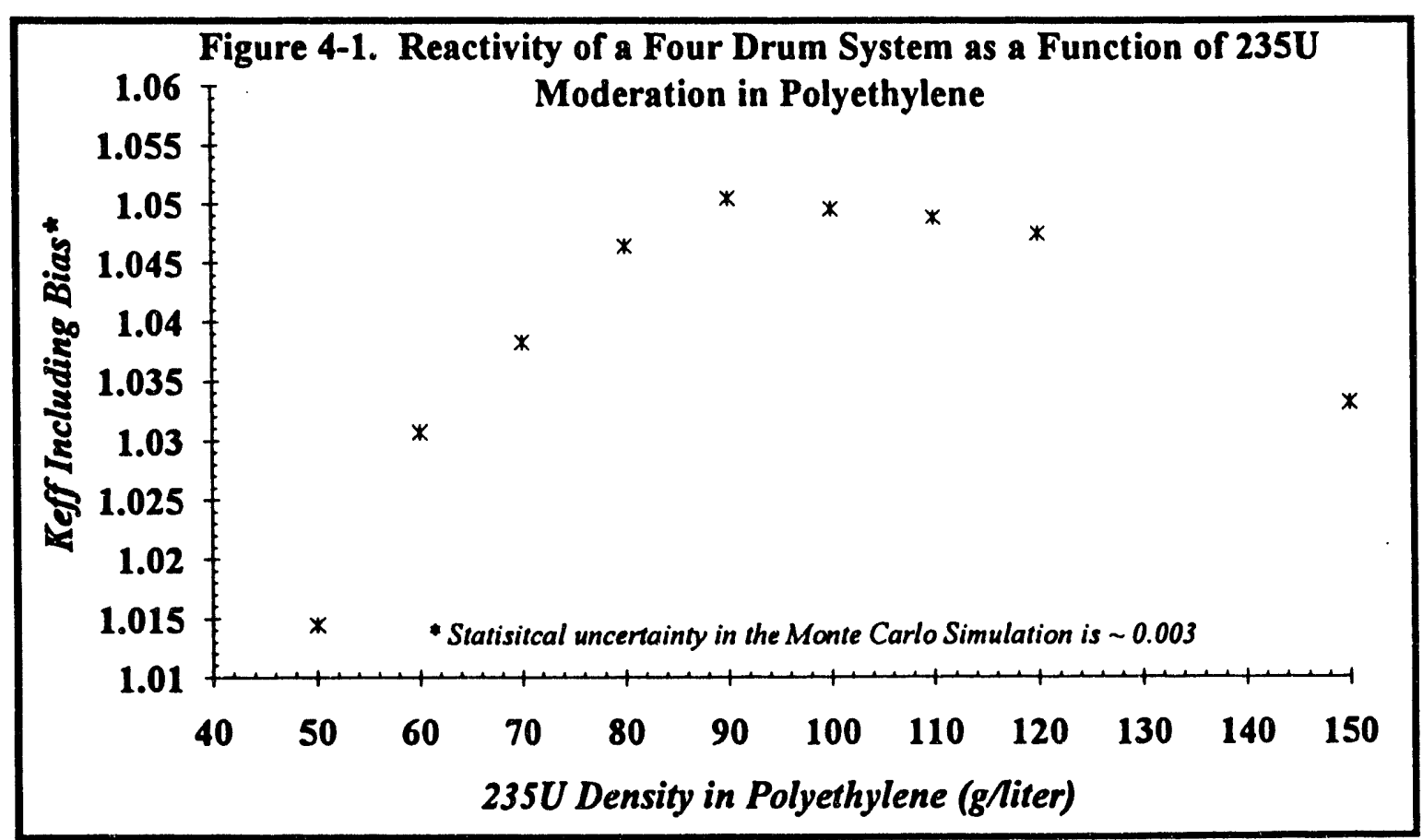


sphere, a $235 \mathrm{U}$ density of 90 gram/liter is selected as the optimum density in polyethylene, which corresponds to a $\mathrm{H}: 235 \mathrm{U}$ ratio of $\approx 340$.

The optimum $235 \mathrm{U}$ density is calculated in a similar manner for other examined configurations. The results, i.e., optimum $235 \mathrm{U}$ density, for the different examined configurations are listed in Table 4-1.

\subsubsection{External Reflector}

Effects of the composition and thickness of the external reflector region on the reactivity were investigated. The reactivity, for the four-drum case, was found to be insensitive to composition and thickness of the external reflector region. This indicates that the intermediate reflector region and the internal reflector region are sufficient for reflecting neutrons back into the fissile regions and minimizing neutron leakage from the system.

Table 4-1. Optimum 235U Density in Polyethylene for the Different Examined Configurations

\begin{tabular}{|c|c|}
\hline Optimum $235 \mathrm{U}$ & Description \\
\hline 1. & FOUR B-25 BOXES \\
\hline \multirow[t]{2}{*}{75} & Fuel region formed by the intersection of a sphere with the boxes. \\
\hline & SIX DRUMS IN A TRIANGULAR PITCH \\
\hline 80 & Fuel region formed by the intersection of a sphere with the drums. \\
\hline \multicolumn{2}{|r|}{ TWO B-25 BOXES WITH TWO 55-GALLON DRUMS } \\
\hline 80 & Fuel region formed by the intersection of a sphere with the containers. \\
\hline \multicolumn{2}{|r|}{ FOUR DRUMS IN A SQUARE PITCH } \\
\hline $\begin{array}{l}90 \\
601 \\
80 \\
200 \\
100 \\
90 \\
80 \\
70\end{array}$ & $\begin{array}{l}\text { Fuel region formed by the intersection of a sphere with the drums. } \\
\text { Fuel region formed by the intersection of a sphere with the drums. } \\
\text { Each drum contains a full sphere for its fissile region each. } \\
\text { Each drum contains one cylinder with a } 5.4 \mathrm{~cm} \text { radius. } \\
\text { Each drum contains two cylinders with a } 5.4 \mathrm{~cm} \text { radius each. } \\
\text { Each drum contains three cylinders with a } 5.4 \mathrm{~cm} \text { radius each. } \\
\text { Each drum contains four cylinders with a } 5.4 \mathrm{~cm} \text { radius each. } \\
\text { Each drum contains five cylinders with a } 5.4 \mathrm{~cm} \text { radius each. }\end{array}$ \\
\hline
\end{tabular}

1 Fuel homogeneously mixed with $\mathrm{H}_{2} \mathrm{O}$ (i.e., $\mathrm{H}_{2} \mathrm{O}$ is the moderator). 
Table 4-2. Neutron Multiplication Factor as a Function of the Composition of the Intermediate Reflector Region

$80 \mathrm{~cm}$ of wet soil as the external reflector Polyethylene as the internal reflector

\begin{tabular}{|c|c|c|c|c|c|}
\hline $\begin{array}{l}\text { Composition of } \\
\text { Intermediate: } \\
\text { Reflector: }\end{array}$ & $\begin{array}{l}\text { Four Drum Case' } \\
\mathrm{K}_{\mathrm{r}} \mathrm{r}^{\mathrm{A}} \text { ? }\end{array}$ & $\mathrm{K}_{\mathrm{it}} \mathbf{i}$ & $(\sigma)$ & Four & casse $3^{3}$ \\
\hline Soill & $(0.004)$ & 0.951 & $(0.006)$ & 0.959 & $(0.004)$ \\
\hline We. & $(0.1$ & 0.950 & $(0.006)$ & 0.960 & $(0.005)$ \\
\hline R & 76 & 0.975 & $(0.006)$ & 0.981 & $(0.005)$ \\
\hline $\mathbf{H}$ & $(0.004)$ & 0.932 & $(0.004)$ & 0.943 & $(0.004)$ \\
\hline Poly & $(0.0$ & 0.921 & $(0.004)$ & 0.935 & $(0.004)$ \\
\hline & 0.916 & 0.905 & $(0.004)$ & 0.930 & $0.004)$ \\
\hline
\end{tabular}

1 Contains 1200 grams of ${ }^{235} \mathrm{U}$ distributed in twelve $5.4 \mathrm{~cm}$ radii cylinders at $90 \mathrm{~g} /$ in polyethylene.

2 Contains 1350 grams of ${ }^{235} \mathrm{U}$ distributed in the region formed by the intersection of a sphere with the drums at $\approx 80 \mathrm{~g} /$.

3 Contains 1070 grams of ${ }^{235} \mathrm{U}$ distributed in the region formed by the intersection of a sphere with the boxes at $\approx 90 \mathrm{~g} / 1$.

$4 \mathrm{~K}_{\text {eff }}$ as calculated by the KENO code without the bias, and values in parentheses are the statistical uncertainty of the calculated $\mathrm{K}_{\text {eff. }}$

\subsubsection{Intermediate Reflector Region}

With wet soil as the external reflector at $80 \mathrm{~cm}$ thick, the composition of the intermediate reflector region was varied for the four drum configuration. The results are shown in Table 4-2. Since the intermediate reflector region is either soil or wet soil, and since the

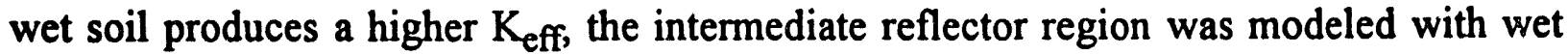
soil for further calculations.

\subsubsection{Internal Reflector}

The reactivity of the four drum configuration model as a function of the interior container reflector region composition is presented in Table 4-3. Table 4-3 indicates that the polyethylene results in a higher reactivity than water. Since the containers contain hydrogenous material in the form of plastic and possibly water (due to water leakage), for further calculations, the internal containers are conservatively modeled to contain polyethylene. 
Table 4-3. Reactivity of the Four Drum Configuration as a Function of the Composition of the Container's Internal Reflector Region

$80 \mathrm{~cm}$ of wet soil as the external reflector

Drums in contact in a square pitch

90 grams/liter of ${ }^{235} \mathrm{U}$ in polyethylene

Wet soil in the intermediate reflector region

\begin{tabular}{|c|c|c|}
\hline $\begin{array}{l}\text { Composition of Container's } \\
\text { Internal Reflector }\end{array}$ & K. $n^{1}$ & $\sigma^{2}$ \\
\hline 12171 Soil & 0.9472 & 0.0032 \\
\hline Wet Soil & 0.9774 & 0.0030 \\
\hline " & 0.9599 & 0.0031 \\
\hline TI Polyethylene & 0.9695 & 0.0035 \\
\hline Void & 0.7660 & 0.0032 \\
\hline
\end{tabular}

$1 \mathrm{~K}_{\text {eff }}$ as calculated by the KENO/CG code without the bias.

2 Statistical uncertainty of the calculated $\mathrm{K}_{\text {eff. }}$

Shown in Figure 4-2 is a plot of $\mathrm{K}_{\text {eff }}$ as a function of the void fraction in the polyethylene internal reflector region. The results indicate that $\mathrm{K}_{\text {eff }}$ is highest for full density polyethylene, i.e., void fraction of zero. For all further calculations, full density polyethylene is employed.

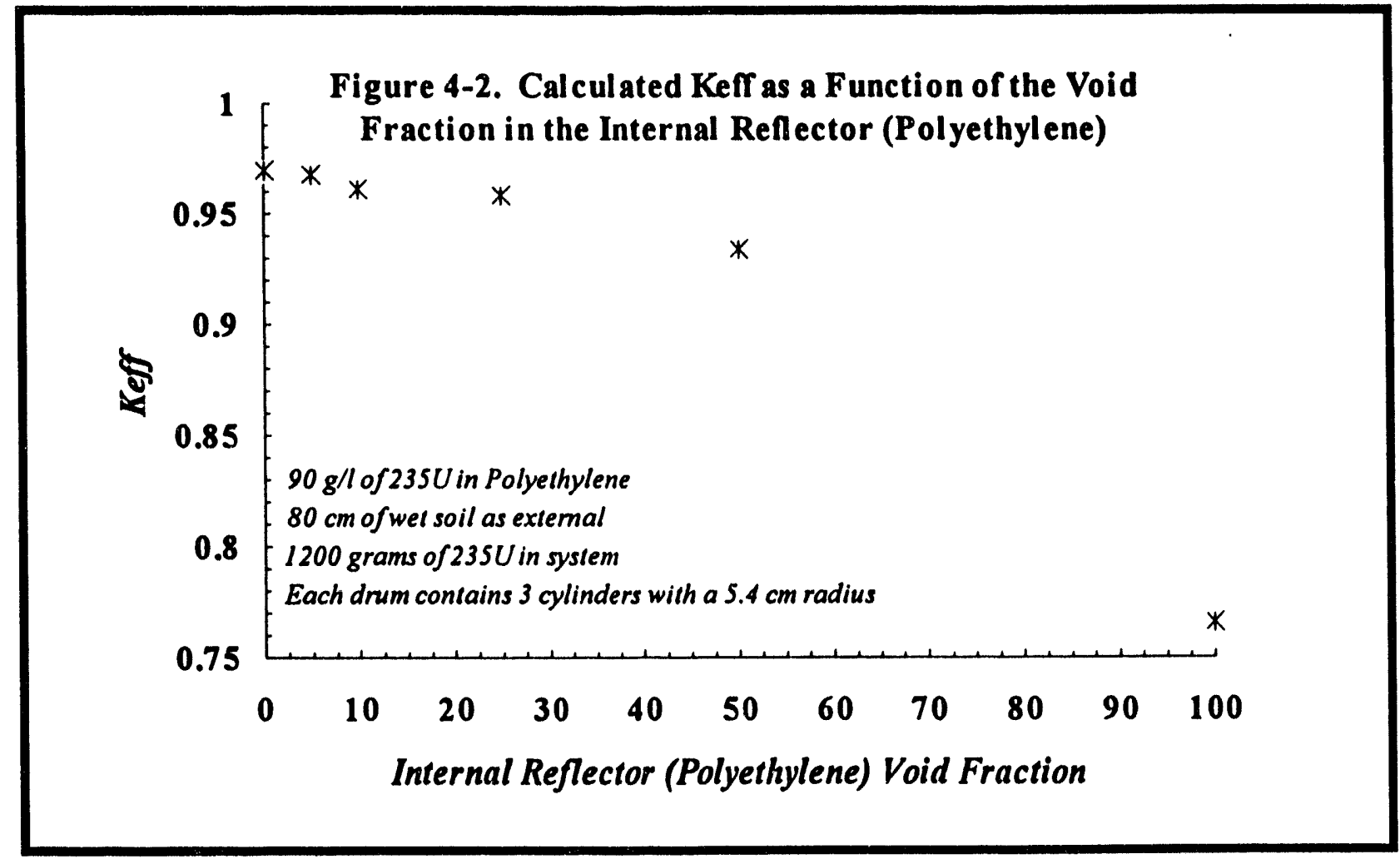




\subsubsection{Containers' Separation Distance}

The reactivity of a system containing various fissile units is a function of two main phenomena: the intrinsic reactivity of each individual unit and the neutronic coupling (neutronic interaction) among the various units. The intrinsic reactivity is dependent on the neutronic characteristics of the fissile units, e.g., quantity and enrichment of the fissile material, moderation, and reflection, while the neutronic coupling depends on the separation distance and moderation between the interacting units and the shape and size of the interacting units. In this part of the study, the effect of separation distance between drums on the overall reactivity was examined.

Due to the rolling hoops, drums in contact have an inner surface-to-inner surface separation distance of $5 / 8$ " (edge-to-edge separation between adjacent fissile regions). Additionally, the vertical separation distance between the fissile region of interacting drums that are in contact is assumed to be 1", refer to Section 3.3.1. Listed in Table 4-4 is the calculated $\mathrm{K}_{\text {eff }}$ as a function of the separation distance between the drums of a four drum system.

Table 4-4. Reactivity of the Four Drum Configuration as a Function of the Separation Distance Between the Drums

$80 \mathrm{~cm}$ of wet soil as the external reflector

Full density polyethylene as the internal reflector

Wet soil in the intermediate reflector region

\begin{tabular}{|c|c|c|c|}
\hline $\begin{array}{c}\text { Drum's Edge-to-Edge } \\
\text { Separation Distance (cm) }\end{array}$ & $\begin{array}{c}\text { Drum's Head-to-Head } \\
\text { Separation Distance (cm) }\end{array}$ & Kert $^{1}$ & $\sigma_{\text {s }}{ }^{2}$ \\
\hline $0.0^{3}$ & $0.0^{3}$ & 0.970 & 0.0035 \\
\hline 0.25 & 0.25 & 0.946 & 0.0035 \\
\hline 0.50 & 0.50 & 0.937 & 0.0033 \\
\hline 0.75 & 0.75 & 0.927 & 0.0035 \\
\hline 1.00 & 1.00 & 0.921 & 0.0035 \\
\hline 1.50 & 1.50 & 0.889 & 0.0033 \\
\hline 2.00 & 2.00 & 0.868 & 0.0037 \\
\hline 0.5 & 0.0 & 0.959 & 0.0039 \\
\hline 0.0 & 0.5 & 0.945 & 0.0037 \\
\hline
\end{tabular}

1 Expected $\mathrm{K}_{\mathrm{eff}}$ as calculated by the KENO/CG code without the bias.

2 Statistical uncertainty of the calculated $\mathrm{K}_{\mathrm{eff}}$.

3 Actual edge-to-edge separation distance between the fissile regions of adjacent drums is $5 / 8$ ".

${ }^{4}$ Actual head-to-head separation distance between the fissile regions of the drums is 1 ". 
The results of Table 4-4 indicate that a decrease in the calculated $\mathrm{K}_{\text {eff }}$ is obtained as the separation distance increases. Additionally, the results indicate that increasing the headto-head separation distance causes a greater decrease in the reactivity than increasing the edge-to-edge separation distance. This indicates that the neutronic coupling among adjacent drums is smaller than the coupling among facing drum.

\subsubsection{Neutronic Interaction Among the Containers}

The assumption of isolated cells within the containers employed in Section 3.3.3 (Statistical Model) of this report are verified in this section. Listed in Table 4-5 are the results of the analysis performed to examine the extent of fissile material isolation within the containers for the 4 B-25 boxes and the four- and six-drum configurations. The results of Table 4-5 indicate that the 55 gallon drums and B-25 boxes can be assumed to have 16 and 175 cells that are neutronically independent.

Table 4-5. $K_{\text {eff }}$ as a Function of the Fissile Material Distribution Within the Containers

\begin{tabular}{|c|c|c|c|c|c|c|}
\hline Description & \multicolumn{2}{|c|}{$\begin{array}{l}\text { Four B-25 Box } \\
\text { System1 }\end{array}$} & \multicolumn{2}{|c|}{$\begin{array}{l}\text { Four 55-Gallon } \\
\text { Drum System² }\end{array}$} & \multicolumn{2}{|c|}{$\begin{array}{l}\text { Six } 55-\text { Gallon } \\
\text { Drum System }\end{array}$} \\
\hline Reference case 4 & 0.962 & $(0.0039)$ & 0.970 & $(0.0026)$ & 0.952 & $(0.0049)$ \\
\hline One sector of fuel removed 5 & 0.905 & $(0.0039)$ & 0.910 & $(0.0028)$ & 0.909 & $(0.0048)$ \\
\hline $\begin{array}{l}\text { One sector of fuel moved up } \\
\text { one cell } 6\end{array}$ & 0.907 & $(0.0040)$ & 0.913 & $(0.0027)$ & 0.903 & $(0.0038)$ \\
\hline $\begin{array}{l}\text { One sector of fuel moved to } \\
90^{\circ} \text { cell? }\end{array}$ & 0.898 & $(0.0040)$ & 0.900 & $(0.0033)$ & 0.910 & $(0.0040)$ \\
\hline
\end{tabular}

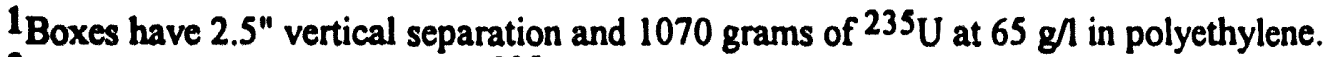

${ }^{2}$ Drums contain $1200 \mathrm{grams}$ of ${ }^{235} \mathrm{U}$ at $90 \mathrm{~g} /$ in polyethylene (each drum contains 3 cylinders with a $5.4 \mathrm{~cm}$ radii).

3 Drums contain 1350 grams of $235 \mathrm{U}$ at $80 \mathrm{~g} /$ in polyethylene.

4 Fuel arranged in most reactive configuration.

5 Each system contains only $75 \%$ or $83 \%$ of the Reference case fuel.

${ }^{6}$ For the B-25 case, one fuel sector moved one cell in the six foot dimension.

${ }^{7}$ For the B-25 case, one fuel sector moved one cell in the four foot dimension. 


\subsubsection{Mass Distribution Among the Containers}

The effects of un-even distribution of the fuel among the containers for the four B-25 boxes and the six drums systems have been examined. In this set of analyses, the total 235U loading in each system was fixed while the loading per container is varied. The results are listed in Table 4-6. The results of Table 4-6 indicate that in general, the most reactive configuration is when all containers have an even mass loading throughout all containers.

Table 4-6. $K_{\text {eff }}$ as a Function of the Fuel Distribution Among the Containers

\begin{tabular}{|c|c|c|c|}
\hline Description & \multicolumn{2}{|c|}{$\begin{array}{l}\text { Fow B-25 Box } \\
\text { System } 1\end{array}$} & $\begin{array}{l}\text { Six 55-Gallon Drum } \\
\text { System² }\end{array}$ \\
\hline Rererrence case ${ }^{3}$ & 0.962 & $(0.0039)$ & $(0.0049)$ \\
\hline $\begin{array}{l}+30 \% \text { In one box } \\
10 \% \text { In remaining three boxes }\end{array}$ & 0.962 & $(0.0045)$ & Not Examined \\
\hline $\begin{array}{l}100 \% \text { in one box } \\
+33 \% \text { in remaining three boxes }\end{array}$ & 0.950 & $(0.0046)$ & Not Examined \\
\hline $\begin{array}{l}100 \% \text { in one drum } \\
20 \% \text { In remaining five drums }\end{array}$ & \multicolumn{2}{|c|}{ Not Examined } & $(0.0042)$ \\
\hline
\end{tabular}

${ }^{1}$ Boxes have $2.5^{\prime \prime}$ vertical separation and 1070 grams of ${ }^{235} \mathrm{U}$ at $65 \mathrm{~g} /$ in polyethylene.

${ }^{2}$ Drums contain $1350 \mathrm{grams}$ of ${ }^{235} \mathrm{U}$ at $80 \mathrm{~g} /$ in polyethylene.

$3^{3}$ Fuel arranged in most reactive configuration.

\subsubsection{Sub-Critical Loading}

Based on the analysis presented in Sections 4.2 .1 through 4.2 .7 , the most neutronically reactive configurations were used in obtaining the sub-critical loading for each examined system. The limiting safe $235 \mathrm{U}$ loading was obtained by varying the $235 \mathrm{U}$ content until a $\mathrm{K}_{\text {eff }}$ safe value of less than 1.0 is obtained. The $\mathrm{K}_{\text {eff }} \mid$ safe is based on the calculated $\mathrm{K}_{\text {eff }}$, the bias of the KENO calculation, and the statistical uncertainty of the calculated $\mathrm{K}_{\text {eff, }}$ as follows:

where:

$$
K_{\left.\infty d\right|^{p a v e}}=K_{\text {df }}+\sigma_{b}\left(H:^{23 s} U\right)+3 \sigma_{\text {s }}
$$


$K_{\infty}:$ the eigenvalue as calculated by the HRXN/KENO modules.

o: bias in the KENO calculated $\mathrm{K}_{\text {eff }}$ defined in Section 2.3.1 and presented by Equation (2-1).

$\sigma_{\text {: }} \quad$ statistical uncertainty in the KENO/CG calculated $\mathrm{K}_{\text {eff }}$

The subcritical 235U mass loading for the various configurations examined in this study are summarized in Table 4-7.

Table 4-7. 235U Safe Loading

\begin{tabular}{|c|c|}
\hline Description & $\begin{array}{l}\text { 235U Mass Limit } \\
\text { (grams)1 }\end{array}$ \\
\hline Four B-25 Boxes with a 2.5 " vertical spacing ${ }^{2}$ & 1070 \\
\hline Four B-25 Boxes with a 0" vertical spacing ${ }^{2}$ & 700 \\
\hline Three B-25 Boxes with a 0" vertical spacing ${ }^{2}$ & 756 \\
\hline Six and Five Drum Configurations ${ }^{2}$ & 1350 \\
\hline $\begin{array}{l}\text { Four Drum Configuration } \\
\text { Fuel region formed by the intersection of a sphere with the drums } \\
\text { Each drum contains a full sphere for its fissile region } \\
\text { Each drum contains one cylinder }{ }^{3} \text { with a height of } 21.8 \mathrm{~cm} \text { each. } \\
\text { Each drum contains two cylinders } 3 \text { with a height of } 17.5 \mathrm{~cm} \text { each. } \\
\text { Each drum contains three cylinders }{ }^{3} \text { with a height of } 12.1 \mathrm{~cm} \text { each. } \\
\text { Each drum contains four cylinders }{ }^{3} \text { with a height of } 10.9 \mathrm{~cm} \text { each. } \\
\text { Each drum contains five cylinders }{ }^{3} \text { with a height of } 11.9 \mathrm{~cm} \text { each. }\end{array}$ & $\begin{array}{c}920 \\
1520 \\
> \\
1400 \\
1280 \\
1200 \\
1280 \\
1520\end{array}$ \\
\hline
\end{tabular}

1 Calculated maximum safe $235 \mathrm{U}$ mass. Based on assay uncertainty, the systems of 4, 5, and 6 containers result in a 20 uncertainty (at $95 \%$ confidence levels) of $7 \%, 6.5 \%$, and $6.1 \%$, respectively, using Equation (3-11). The 20 uncertainty for these configurations are $5.4 \%, 5.0 \%$, and $4.6 \%$, respectively, when Equation (3-10) is employed. Equation (3-11) was used in the original study and its use, although not accurate, results in uncertainty levels that are higher than those calculated by Equation (3-10). This causes the ${ }^{235} \mathrm{U}$ safe loadings listed in this table to be reduced more than needed.

2 Fuel region formed by the intersection of a sphere with the containers.

3 Each cylinder radius fixed at $5.4 \mathrm{~cm}$. 


\subsection{STATISTICAL ANALYSIS}

The expectation values for obtaining 4, 3, or 6 drums in a close packed array that exceed the subcritical 235U mass loading (listed in Table 4-7) minus $2 \sigma$ (assay uncertainty) are listed in Table 4-8. These expectation values were obtained using the procedure outlined in Section 3.3.3 of this document and in Reference 7. The mass loadings of the drums in the various trench areas were obtained from the COBRA data base [13].

Table 4-8. Expectation Values for Drum Combinations Exceeding Subcritical Mass Loading

\begin{tabular}{|c|c|c|c|c|c|}
\hline Trench Area & $\begin{array}{c}\text { Region } \\
\text { East- } \\
\text { Coordinate }\end{array}$ & $\begin{array}{c}\text { North- } \\
\text { Coordinate }\end{array}$ & $\begin{array}{c}\text { Six Drums } \\
(>1267 \mathrm{~g}) \mathbf{1}^{1}\end{array}$ & $\begin{array}{c}\text { Five Drums } \\
(>1267 \mathrm{~g})^{2}\end{array}$ & $\begin{array}{c}\text { Four Drums } \\
(>1116)^{3}\end{array}$ \\
\hline One & 17.40 & $29.60-30.90$ & 0.160 & 0.079 & 0.004 \\
\hline One & $12.75-12.85$ & 31.50 & 0.012 & 0.001 & 0.000 \\
\hline One & $13.05-13.20$ & 31.50 & 0.073 & 0.031 & 0.020 \\
\hline Three & $20.65-20.80$ & 11.90 & 0.028 & 0.012 & 0.000 \\
\hline Five & 29.60 & $17.25-17.50$ & 0.002 & 0.000 & 0.000 \\
\hline
\end{tabular}

1 Actual calculated minimum critical mass reduced by $6.1 \%$ to arrive at 1267 grams.

2 Six drum ${ }^{235} \mathrm{U}$ limit was conservatively taken as limit for the five drum casebased on the results of Table 4-6.

3 Actual calculated minimum critical mass reduced by $7 \%$ to arrive at $1116 \mathrm{grams}$. 


\section{S.1 INTRODUCTION}

Results of the nuclear criticality safety and statistical calculations are summarized in this section. The probabilities for obtaining a critical mass from the various waste container configurations are determined and summarized in this section.

\subsection{BOXES}

The limiting reactivity for four boxes with the lifting lugs intact was found to be with a content of 1070 grams total, as shown in Table 4-7. Including the 2- $\sigma$ uncertainty of 7\%1 reduces the assay limit to 1000 grams. A statistical evaluation of the probability for finding combinations of three or four boxes containing more than limiting masses of 630 , 700 , or 820 grams has been made [17]. That analysis concluded the following:

$>$ The expectation value for 3 or 4 adjacent boxes summing to 1000 grams is zero.

- The 700 gram case for 3 boxes is applicable to the present evaluation, with a summed probability (expectation value) of 0.01043 .

$>$ The probability was very low for finding 4 boxes summing to 700 grams in which the highest 3 did not independently sum to 700 grams. For example, in ELLT2, the probability of a critical configuration summing to 700 grams or more of $235 \mathrm{U}$ in for a 4 box configuration in which the highest 3 did not sum up to 700 grams is $5.7 \times 10^{-06}$ [18]. This fact coupled with the added reduction of the internal distribution probability by an added factor of $1 / 175$ reduces consideration to the 3 box geometry only.

The probability for finding the required optimum internal distribution is found from the following argument:

${ }^{1}$ The $2 \sigma$ uncertainty for this configuration is actually $5.4 \%$ when Equation $(3-10)$ is employed. Equation (3-11) was used in the original study and its use, although not accurate, results in uncertainty levels that are higher than those calculated by Equation (3-10). This causes the reduced ${ }^{235} \mathrm{U}$ safe loadings listed in this table to be lower than needed. 
In the first box considered the fuel must be found in one of the seven cells along the edge common to all three boxes. This probability is $7 / 175$. The fuel in the final two boxes must be in the single cell adjacent to that in which the fuel was located in the first box. This probability is $1 / 175$ for each, giving a total probability of $1.31 \times 10^{-06}$ for the internal distribution. The combined probability is $1.37 \times 10^{-}$ 08 .

\subsection{SIX AND FIVE DRUMS}

The KENO computations for six drums give a limit of 1350 grams total, as shown in Table 4-7. The computed expectation value for 6 drums summing to a 1272 grams (1350 grams minus 2 sigma) was 0.275 for six drums. Since this also includes 5 drums summing to the same value, the 5 drum case was also evaluated for the same 1272 gram limit. The expectation value here was 0.123 , leaving 0.152 for the 6 drum case. Combined with the internal distribution, one obtains a maximum criticality probability of $9.05 \times 10^{-09}$ for the 6 drum case and $1.173 \times 10^{-07}$ for the 5 drum case.

\subsection{FOUR DRUMS}

The KENO computations give a limit of 920 grams total for the four-drum combination when the fissile region of the system is assumed to be formed by the intersection of a sphere with the drums. However, when credit is taken for the fact that low-level solid waste is packaged in 2-liter cardboard containers $(5.4 \mathrm{~cm}$ radius), the $235 \mathrm{U}$ limit increases to 1200 grams (case in which each drum contains three cardboard boxes, as shown in Table 4-7). For the statistical analysis, the 1200 gram limit is chosen, i.e., credit is taken for the way that low-level solid waste is packaged. The computed expectation value for four drums summing to 1122 grams (1200 grams minus 2 sigma) is 0.024 . Combined with the internal distribution, one obtains a maximum probability for criticality of $3.20 \times$ $10-07$

\subsection{INTERACTING BOXES AND DRUMS}

In ELLT3 a number of drums have been piled up against boxes presenting the possibility of drum/box interaction. For this combination, the geometric arrangement having the highest criticality potential is with the bottom of two touching drums placed flat against the ends of the boxes, as shown in Table 4-7. The KENO limiting concentration for this case is $\mathbf{8 0 0}$ grams. A number of combinations of drums at this site and boxes in the 
vicinity sum to this value, so it is necessary to use statistical arguments. The probability for internal locations for 2 drums and 2 boxes is $1.276 \times 10^{-07}$, i.e., $(1 / 16)^{2} \times(1 / 175){ }^{2}$ The method for conservatively estimating the expectation value that 2 drums and 2 boxes will be juxtaposed so as to exceed the critical mass is discussed above. The value obtained is $\mathbf{0 . 1 1 8}$. Combined with the internal probability this gives a net probability of $0.15 \times 10^{-07}$.

\subsection{ENTIRE SYSTEM}

The conservatively estimated probability sums to $0.467 \times 10^{-06}$. It should be emphasized that large margins of safety have been embedded in the modeling and are not accounted for in the analysis. That is, the safety margins embedded in the modeling would cause the probability of a criticality to decrease further. The safety margins include the following:

$>$ The assumption of an orderly close-packed arrangement of the drums: drums are more or less randomly distributed and oriented with soil spacing common between drums. This makes it unlikely that more than two drums will be in close proximity around a common point. Random spacing will tend to increase the separation distance between interacting volumes. The assumption of orderly spacing adds a very large but un-quantifiable margin of safety for the drums and for the interacting drums and boxes, but not for the boxes considered alone.

$>$ The assumption that the Waste Management procedure requiring separation of EU containers has been violated [4], i.e., "Enriched uranium (Type 20) burials must be separated from all other shipments by a minimum of 3 horizontal feet of earth or $1 \mathrm{~B}-25$ box for engineered low level trench (ELLT) operation when buried," and that "No other shipment of enriched uranium will be buried in the same North-East coordinates." In this analysis, it was assumed that four B-25 boxes containing EU can be placed edge-to-edge.

$>$ The effect of periodic earth (soil) layers between the drums as well as the numerous other "clean" waste materials buried along with the drums have been neglected.

The assumption that the box lifting lugs on the bottom of the B-25 boxes have collapsed or that they made deep indentations in the box immediately below. 
The assumption that the distribution of fuel among the cells of the containers (175 for the B-25 boxes and 16 for the 55-gallon drums) has equal probability, refer to Section 2.4 .3 for further detail.

$>$ The assumptions of optimum geometrical distribution and optimum moderation and reflection within each container, which include the following:

$\checkmark$ The assumption of full density polyethylene in the containers. The containers are expected to contain hydrogenous material in the form of plastic and possibly water (due to water leakage), voids, and other materials that may have neutron-absorbing properties higher than hydrogenous materials.

$\checkmark$ The assumption that the residual $25 \%$ of the soil's theoretical volume is filled with $\mathrm{H}_{2} \mathrm{O}$ (Section 2.4.2). Additionally, the density of the soil was assumed to be $106 \%$ of its nominal value and the organic matter in the soil is in the form of $\mathrm{CH}_{2}$.

$\checkmark$ The assumption of the fuel being at optimum density, i.e., optimum $\mathrm{H}:{ }^{235} \mathrm{U}$ ratio.

\subsection{CONCLUSIONS}

Although conservative assumptions were employed throughout the analysis, which are summarized in Section 5.6, the analysis concluded that the potential of a nuclear criticality in the as-is configuration of the LLRWDF is incredible. The combined probability of a criticality in the LLRWDF (in ELLT 2 and ELLT 3 and in the seven slit trenches of interest) was conservatively estimated to be $0.47 \times 10^{-06}$. 


\subsection{REFERENCES}

1. Procedure Manual E7, "Conduct of Engineering and Technical Support (U)," Westinghouse Savannah River Company, Aiken, SC.

2. R.A. Knief, "Nuclear Criticality Safety: Theory and Practice," American Nuclear Society, La Grange Park, Illinois (1991).

3. A.G. Sarrack, J.H. Weber, and N.D. Woody, "Criticality Assessment of LLRWDF Closure (U)," WSRC-RP-92-974, Westinghouse Savannah River Company, Aiken, SC, October 1992.

4. DPSOL 643-G-2013-Q, "Burying Waste Containing Enriched Uranium," Revision 15, Westinghouse Savannah River Company, Aiken, SC.

5. American Nuclear Society Standards Committee: Subcommittee ANS-8, "American National Standard for Nuclear Criticality Safety in Operations with Fissionable Materials Outside Reactors," ANSI/ANS-8.1-1983, American Nuclear Society, La Grange Park, Illinois October 7, 1983.

6. N.D. Woody, "Criticality Analysis for LLRWDF Trenches (U)," SRT-EAG-93-8002, Westinghouse Savannah River Company, Aiken, SC, March 1993.

7. N.P. Baumann and S.D. Kahook, "Nuclear Criticality Safety Assessment of the Low Level Radioactive Waste Disposal Facility (LLRWDF) Trenches (U)," SRT-CMA93-0023, Westinghouse Savannah River Company, Aiken, SC, June 1993.

8. H.K. Clark, "Effect of Distribution of Fissile Material on Critical Mass," Nuclear Science and Engineering, Vol. 24, pp. 133-141 (1966).

9. H.K. Clark, "JOSHUA Nuclear Criticality Safety Modules: User's Manual," DPSTM-86-700-3, Savannah River Plant, E.I. DU Pont DE Nemours and Company, Inc., March 1987.

10. G.E. Hansen and W.H. Roach, "Six- and Sixteen-Group Cross Sections for Fast and Intermediate Critical Assemblies," LAMS-2543, Los Alamos National Labotatory (1961).

11.H.K. Clark, "Subcritical Limits for Uranium-235 Systems," Nuclear Science and Engineering, Vol. 81, pp. $351-378$ (1982). 
12. T.G. Williamson and N.P. Baumann, "Intersecting Volumes - Spheres with Cylinders and Boxes," SRT-CMA-920047, Westinghouse Savannah River Company, Aiken, SC, April 1993.

13. M.J. Murnan, "Evaluation of the COBRA Data Files for Seven LLRWDF Slit Trenches in Support of the LLRWDF Criticality Analysis," SRT-RST-930193, Westinghouse Savannah River Company, Aiken, SC, April 1993.

14.J.W. Roxlo, "Naval Fuel Material Facility: Accuracy Estimates of the FMF Waste Disposal Measurements," NSS-6612, Savannah River Plant, E.I. DU Pont DE Nemours and Company, Inc., March 1988.

15.J.L. Jaech, "Statistical Methods in Nuclear Material Control," TID-26298, Technical Information Center, Office of Information Services, Washington, D.C. (1973).

16. Erwin Kreyszig, "Advanced Engineering Mathematics," 6th Edition, John Wiley and Sons, Inc., New York, New York (1988).

17. J.H. Weber, "B-25 Boxes with Significant 235U," SRT-ASG-93-0021, Westinghouse Savannah River Company, Aiken, SC, March 1993.

18. J.H. Weber, "Probability Calculation for Criticality Assessment of LLRWDF Compaction (U)," SRT-EAG-92-9002, Westinghouse Savannah River Company, Aiken, SC, October 1992. 


\section{APPENDIX A}

Presented in this appendix is the derivation of a model that calculates the assay uncertainty (total $235 \mathrm{U}$ mass loading) in a configuration of $\boldsymbol{n}$ containers. The original study documented in [7] erroneously used an equation, reproduced as Equation (A-3) in this report, that over estimated the uncertainty in the total mass loading of ${ }^{235} \mathrm{U}$.

The measured ${ }^{235} \mathrm{U}$ content in the $\mathrm{i}^{\text {th }}$ container, accounting for the relative random error $\left(\varepsilon_{\mathrm{ri}}\right)$ and relative systematic error ${ }^{1}\left(\varepsilon_{\mathrm{s}}\right)$ [15], can be represented by the following Equation:

$$
X_{i}^{m}=X_{i}^{0}\left(1+\varepsilon_{r i}+\varepsilon_{s}\right)
$$

where $X_{i}^{m}$ and $X_{i}^{0}$ are the measured and actual ${ }^{235} \mathrm{U}$ content in the $\mathrm{i}^{\text {th }}$ container. The form in which Equation (A-1) is presented assumes that both $\varepsilon_{\mathrm{ri}}$ and $\varepsilon_{\mathrm{s}}$ have zero means [15]. Alternatively, Equation (A-1) can be written as follows:

$$
X_{i}^{m}=X_{i}^{0} \varepsilon_{i} \varepsilon_{s}
$$

when both $\varepsilon_{\mathrm{ri}}$ and $\varepsilon_{\mathrm{s}}$ have means of one [15]. Although Equations (A-1) and (A-2) are not equivelant, they would yield equivelant results when employed to calculate the variance of $X_{i}^{m}$. In deriving the model for calculating the assay uncertainty (total ${ }^{235} \mathrm{U}$ mass loading) in a configuration of $n$ containers, the form of Equation (A-1) will be used.

Then, if $Z^{m}$ is the total measured ${ }^{235} \mathrm{U}$ content for a given configuration (system represented by $n$ containers), $Z^{m}$ can be given by the following Equation when the form of Equation (A-1) is used:

$$
Z^{m}=\sum_{i=1}^{n} X_{i}^{m}=\sum_{i=1}^{n} X_{i}^{0}\left(1+\varepsilon_{r i}+\varepsilon_{s}\right)=\sum_{i=1}^{n} X_{i}^{0}+\sum_{i=1}^{n} \varepsilon_{r i} X_{i}^{0}+\varepsilon_{s} \sum_{i=1}^{n} X_{i}^{0}
$$

Let the actual total ${ }^{235} \mathrm{U}$ content in a given configuration be represented by $Z^{\circ}$. The value of $Z^{0}$ is equal to the following:

1The systematic error is the error involved in the calibration of the instruments used in estimating the ${ }^{235} \mathrm{U}$ mass loading in a given container. 


$$
Z^{0}=\sum_{i=1}^{n} X_{i}^{0}
$$

Since the random errors of all $i$ containers are assumed to be independent of each other and independent of the systematic error, and both random and systematic errors have zero means [15], then the variance of the sum, i.e., the variance of $Z^{m}, V\left(Z^{m}\right)$, is given by the following:

$$
V\left(Z^{m}\right)=v\left(\varepsilon_{r i}\right) \sum_{i=1}^{n}\left[X_{i}^{0}\right]^{2}+v\left(\varepsilon_{s}\right)\left[\sum_{i=1}^{n} X_{i}^{0}\right]^{2}
$$

where $v\left(\varepsilon_{r i}\right)$ and $v\left(\varepsilon_{s}\right)$ are the relative variances of the random and systematic errors, respectively.

In this study, the effects of mass distribution among the containers were investigated. The results, which are presented in Section 4.2.7 and Table 4-6, indicate that the most reactive configuration is when all containers have an even mass distribution. Therefore, and as an added conservatism, all containers are assumed to have the same ${ }^{235} \mathrm{U}$ loading, i.e., $X_{i}^{m}=X_{j}^{m}$ for all $i$ containers in a given configuration. This assumption implies the following:

$$
\sum_{i=1}^{n}\left[X_{i}^{0}\right]^{2}=n\left[X_{i}^{0}\right]^{2}
$$

and

$$
\left[\sum_{i=1}^{n} X_{i}^{0}\right]^{2}=n^{2}\left[X_{i}^{0}\right]^{2}
$$

Substituting Equations (A-6) and (A-7) into Equation (A-5) and dividing both sides of the resultant Equation by $n^{2}\left[X_{i}^{0}\right]^{2}$ the relative variance is obtained, which is equal to:

$$
v\left(Z^{m}\right)=\frac{V\left(Z^{m}\right)}{n^{2}\left[X_{i}^{0}\right]^{2}}=\frac{v\left(\varepsilon_{r}\right)}{n}+v\left(\varepsilon_{s}\right)
$$

The relative error of $Z^{m}$, i.e., standard deviation of $Z^{m}$, is just the square root of its relative variance, that is

$$
\sigma_{Z}=\sqrt{\nu\left(\varepsilon_{s}\right)+\frac{\nu\left(\varepsilon_{r}\right)}{n}}=\sqrt{\sigma_{\varepsilon_{i}}^{2}+\frac{\sigma_{\varepsilon_{r}}^{2}}{n}}
$$


where:

$\sigma_{Z^{*}}$ : overall uncertainty in the mass loading of ${ }^{235} \mathrm{U}$ for the examined configuration with $n$ containers;

$\sigma_{\varepsilon_{i}}: \quad$ systematic error of the Low Density Scrap Assay system (1\%); and

$\sigma_{\varepsilon}: \quad$ random error $(5 \%)$

Applying Equation (A-9) to the systems of 4, 5, and 6 containers result in a $\sigma_{Z}$ uncertainty of $\approx 2.7 \%, \approx 2.5 \%$, and $\approx 2.3 \%$, respectively. The assay uncertainties for a system (configuration) of 4,5 , and 6 containers with a $95 \%$ confidence level, i.e., $2 \sigma_{Z}$ uncertainty, are $\approx 5.4 \%, \approx 5.0 \%$, and $\approx 4.6 \%$, respectively. 

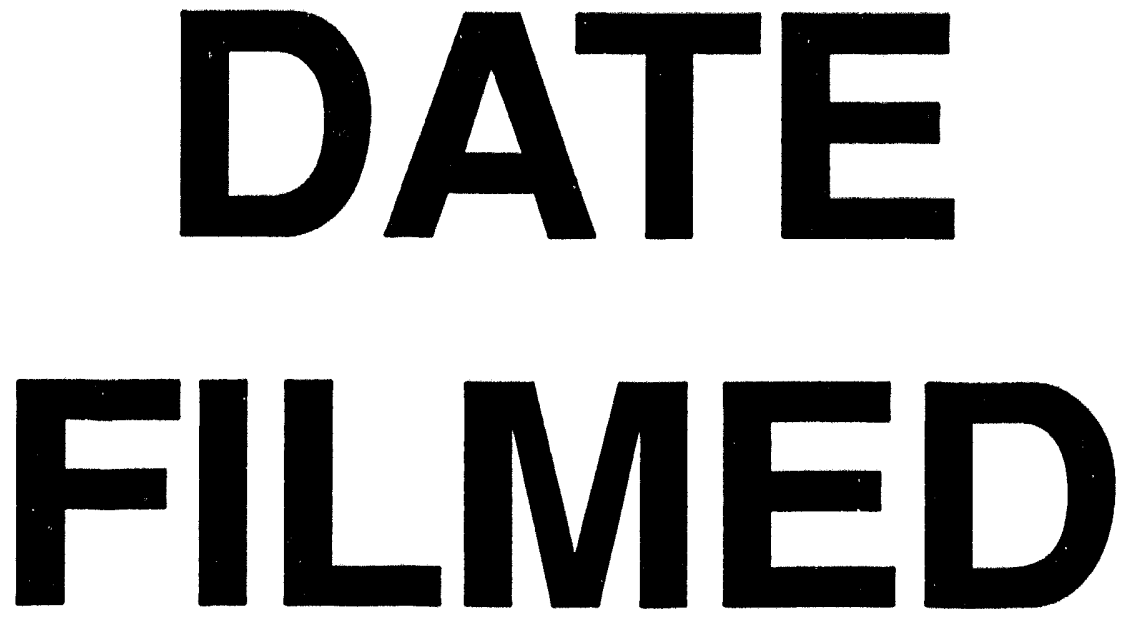

$6 / 28 / 94$
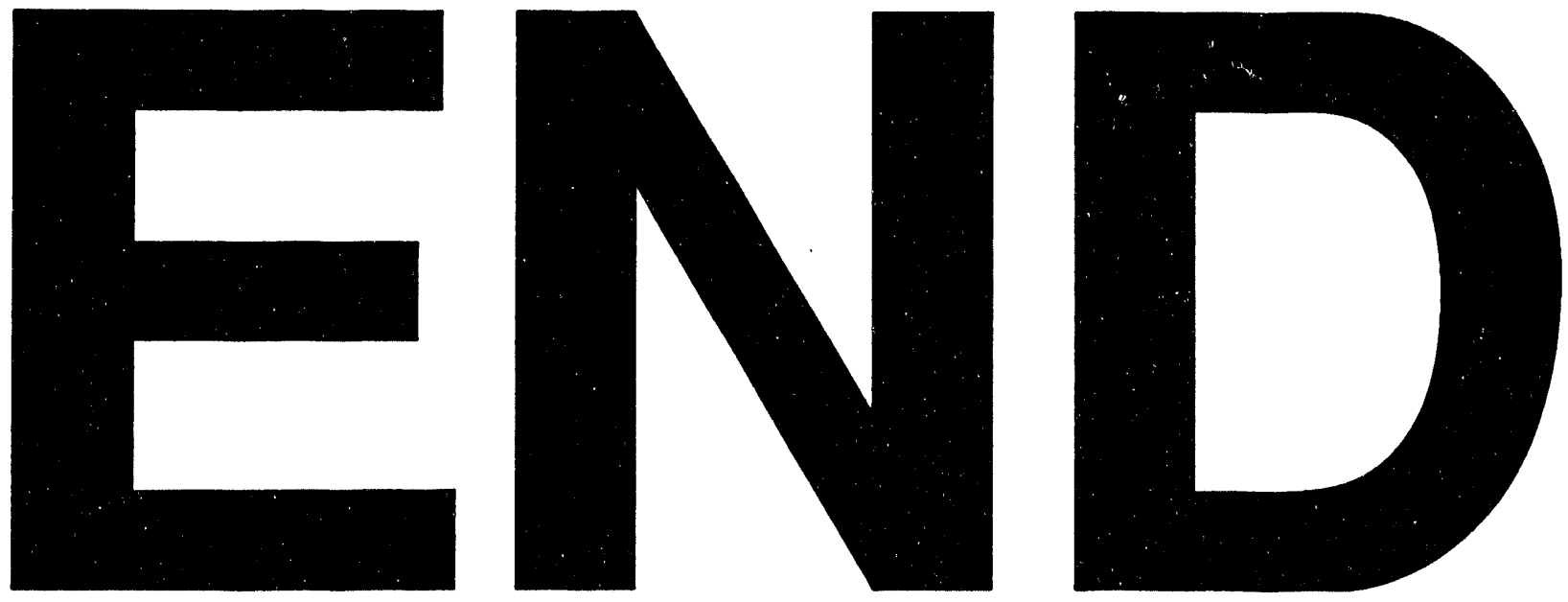
